\title{
The mathematical treatment of grid-survey data for land levelling
}

\author{
J. L. UNGER
}

International Land Development Consultants Ltd., Arnhem, Netherlands

\section{Contents}

$S$ u m m r y

2. Sources of errors and theirelimination

1. Introduction

2.1. The mathematical error in grid squares where cut changes to fill

2.2. Elimination of the mathematical error in grid squares where cut changes to fill

2.3. The evaluation of volumes of cut and fill in grid squares traversed by the plot's boundaries

2.4. Some practical examples

3. Tentative comparison between calculated and true volumes

\section{Summary}

The accuracy of three methods of calculating the volumes of earth movement for land levelling on account of grid-point data is investigated, viz. of the summation, four-point and stereometric method.

Two sources of errors appear to be responsible for obvious inaccuracies caused by the application of the summation method:

a. a systematic error in grid squares, where cut changes to fill;

b. a statistical inaccuracy when evaluating the volumes of earth movement in grid squares traversed by the boundaries of the plot to be levelled.

It is demonstrated that the four-point method is subject to a similar deficiency as mentioned under a, though to a much lesser degree than the summation method, but does not show the deficiency mentioned under $b$. The stereometric method appears to be free from both deficiencies. In grid squares with all corners either in cut or in fill and not traversed by the plot's boundaries, each calculation method gives the same results.

When the deficiency mentioned under $b$ is eliminated, all three calculation methods give the same earth-work balance for a plot to be levelled.

The stereometric calculation as such being too complicated for practical application, it is found to be practicable to correct the summation method in such a way as to obtain results which are identical to those of the stereometric method, especially, when tabular aids or nomographs are used and the survey is made with the aid of a triangular net instead of a net of grid squares.

When the number of grid squares, where cut changes to fill, is comparatively small, results identical to those of the four-point method are obtained more quickly by applying a correction to the summation method than by applying the four-point method as such.

The various calculations with the aid of corrections are demonstrated by practical examples.

A tentative comparison is made between calculated and true volumes. The stereometric calculation appears to give the closest approximation.

\section{Introduction}

The mathematical treatment of cut and fill figures calculated as the difference in Received for publication 28th March, 1963. 
elevation at grid points between the present surface of the land and a given, more suitable land surface to be obtained in future, will be discussed.

This problem especially occurs when land is prepared for irrigated agriculture. Neither the adequacy of the grid system in view of the present topography nor the requirements and determination of the future land surface will be dealt with.

The discussion will further be restricted to calculation methods making use of cut and fill figures per grid point only, i.e. without the determination of cross sectional areas (end-area method) or areas between contours or lines of equal cut and fill (horizontal-plane method) ${ }^{1}$. Three calculation methods will be compared:

the summation method;

the four-point method;

the stereometric method.

The accuracy and the laboriousness of these methods will be investigated.

\section{Sources of errors and their elimination}

It will be demonstrated that two purely mathematical sources of errors exist, resulting from inaccurate calculation of the volumes of cut and fill in grid squares, where cut changes to fill, and from a less precise evaluation of the volumes contributed by grid squares traversed by the plot's boundary.

\subsection{The mathematical erroringridsquares wherecut changes to fill}

Each of the three above-mentioned methods of calculation makes use of imaginary surfaces bounding the volume of earth to be moved per grid square, viz. the four plane sides of the square and the present and future land surfaces. The two latter surfaces are represented in a highly schematic way only.

When applying the summation method, the present and future surfaces are represented as consisting of plane, horizontal squares situated at the present and future elevation as determined at each grid point. The grid points are situated in the centre of each square. The earth volume to be moved per grid square is calculated according to the formula :

$\mathrm{V}_{\mathrm{c}}=\mathrm{L}^{2} \mathrm{c}$ and $\mathrm{V}_{\mathrm{f}}=\mathrm{L}^{2} \mathrm{f}$

$c$ and $f=$ the difference between the present and future elevation, positive in case of cut, negative in case of fill

$\mathrm{L}=$ grid spacing

The total volume of cut and fill :

$$
\mathrm{C}=\mathrm{L}^{2}[\mathrm{c}] \text { and } \mathrm{F}=\mathrm{L}^{2}[\mathrm{f}]
$$

According to the four-point method the volumes are calculated as follows:

$$
\begin{aligned}
& \text { per grid square: } V_{c}=\frac{L^{2}}{4} \times \frac{H_{c}^{2}}{H_{c}+H_{f}} \text { and } V_{f}=\frac{L^{2}}{4} \times \frac{H_{f}^{2}}{H_{c}+H_{f}} \\
& H_{c}=\text { sum of cuts on four corners of a grid square } \\
& H_{f}=\text { sum of fills on four corners of a grid square }
\end{aligned}
$$

1 See: SCS National Engineering Handbook, section 15 Irrigation, Chapter 12 Land Levelling. SCHEWIOR, Erdmassenberechnung und -Förderweite. 
Total : $\quad \mathrm{C}=\frac{\mathrm{L}^{2}}{4}\left[\frac{\mathrm{H}_{\mathrm{c}}{ }^{2}}{\mathrm{H}_{\mathrm{c}}+\mathrm{H}_{\mathrm{f}}}\right]$ and $\mathrm{F}=\frac{\mathrm{L}^{2}}{4}\left[\frac{\mathrm{H}_{\mathrm{f}}{ }^{2}}{\mathrm{H}_{\mathrm{c}}+\mathrm{H}_{\mathrm{f}}}\right]$

Here, grid squares with the grid points on four corners are considered. If all corners are in cut or in fill, the results are :

$$
\begin{aligned}
& \mathrm{V}_{\mathrm{c}}=\frac{\mathrm{L}^{2}}{4} \mathrm{H}_{\mathrm{c}} \text { and } \mathrm{V}_{\mathrm{f}}=\frac{\mathrm{L}^{2}}{4} \mathrm{H}_{\mathrm{f}} \\
& \mathrm{C}=\frac{\mathrm{L}^{2}}{4}\left[\mathrm{H}_{\mathrm{c}}\right] \text { and } \mathrm{F}=\frac{\mathrm{L}^{2}}{4}\left[\mathrm{H}_{\mathrm{f}}\right]
\end{aligned}
$$

Since in this case $H_{c}=4 c$ and $H_{f}=4 \mathrm{f}$, the results are identical to those, obtained by means of the summation method.

When calculating the volumes stereometrically, the problem arises that the elevations of the present surface, measured at the grid points at four corners of a grid square, seldom or never $l y$ in one and the same plane, not even if all corners are in cut or in fill.

Consequently, two volumes are calculated on account of survey data being restricted to the present and future elevations at the grid points only. This situation is represented in FIG. 1. Since both cases are equally likely to occur, the mean volume should be considered as the best approximation of the reality.
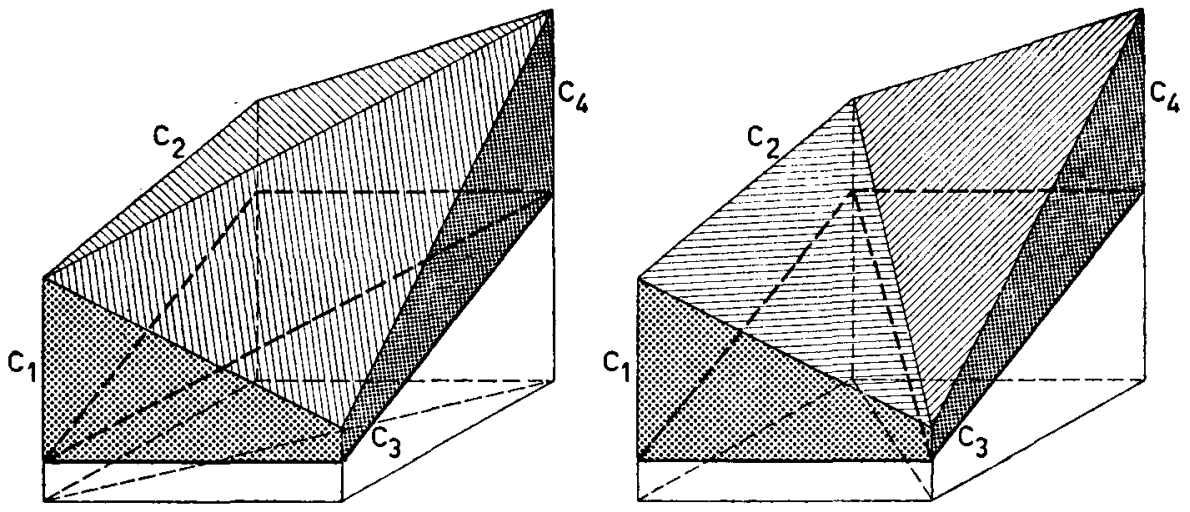

FIGURE 1

For the sake of comparison, the volumes have been calculated according to the three methods already mentioned. The stereometric volumes are calculated as the sum of two three-sided prisms. In this example all corners are considered to be in cut. It needs no explanation that the results will be analogous for all corners in fill. 
summation

four point

stereometric, when divided by diagonal plane $1-4$

by diagonal plane $2-3$

stereometric mean

$$
\begin{aligned}
& V_{c}=\frac{1}{4} L^{2}\left(c_{1}+c_{2}+c_{3}+c_{4}\right) \\
& V_{c}=\frac{1}{4} L^{2}\left(c_{1}+c_{2}+c_{3}+c_{4}\right) \\
& V_{c}=\frac{1}{6} L^{2}\left(2 c_{1}+c_{2}+c_{3}+2 c_{4}\right) \\
& V_{c}=\frac{1}{6} L^{2}\left(c_{1}+2 c_{2}+2 c_{3}+c_{4}\right) \\
& V_{c}=\frac{1}{4} L^{2}\left(c_{1}+c_{2}+c_{3}+c_{4}\right)
\end{aligned}
$$

The results appear to be identical when all corners are in cut (or in fill).

Consequently the differences between the volumes calculated according to the three methods are all 0 and the ratios $=1$. Furthermore, situations remain to be investigated where some corners are in cut and some in fill, in other words where cut changes to fill within the grid square under consideration. Then, a comparison of the differences and the ratios of the volumes calculated after the various methods will demonstrate that the results are not identical but that the deviations are sufficiently systematic to allow corrections.

The conceivable combinations of cut and fill in four corners of a grid square are the following :

a. Three points in cut, one point in fill

b. Three points in fill, one point in cut

c. Two adjacent points in cut and in fill

d. Two points in cut and two points in fill at diagonal corners.

Situation $b$ being analogous to a needs no separate consideration. The three remaining situations give the following results :

Situation a (FIG. 2)


Figure 2 
J. L. UNGER

Fill :

$$
\begin{aligned}
& \text { summation } \quad V_{\mathrm{f}}=\frac{1}{4} \mathrm{~L}^{2} \mathrm{f} \\
& \text { four point } \\
& \text { stereometric, when divided } \\
& \text { by diagonal plane } 1-4 \\
& \mathrm{~V}_{\mathrm{f}}=\frac{1}{4} \mathrm{~L}^{2} \frac{\mathrm{f}^{2}}{\mathrm{c}_{1}+\mathrm{c}_{2}+\mathrm{c}_{4}+\mathrm{f}} \\
& V_{f}=\frac{1}{6} L^{2} \frac{f^{3}}{\left(f+c_{1}\right)\left(f+c_{2}\right)} \\
& \text { by diagonal plane 2-3 } \quad V_{f}=\frac{1}{6} L^{2}\left\{\frac{f^{3}}{\left(f+c_{1}\right)\left(f+c_{2}\right)}+\frac{f^{3}}{\left(f+c_{2}\right)\left(f+c_{4}\right)}\right\} \\
& \text { stereometric mean } \quad V_{f}=\frac{1}{12} L^{2} f^{3}\left\{\frac{3 f+c_{1}+c_{2}+c_{4}}{\left(f+c_{1}\right)\left(f+c_{2}\right)\left(f+c_{4}\right)}\right\} \\
& \text { difference summ. - stereom. } \frac{1}{12} L^{2} f\left\{3-f^{2} \frac{3 f+c_{1}+c_{2}+c_{4}}{\left(f+c_{1}\right)\left(f+c_{2}\right)\left(f+c_{4}\right)}\right\} \\
& \text { difference f.p. }- \text { stereom. } \frac{1}{12} L^{2} f\left\{\frac{3}{f+c_{1}+c_{2}+c_{4}}-f \frac{3 f+c_{1}+c_{2}+c_{4}}{\left(f+c_{1}\right)\left(f+c_{2}\right)\left(f+c_{4}\right)}\right\} \\
& \text { ratio summ. : stereom. } \quad 3 \frac{\left(f+c_{1}\right)\left(f+c_{2}\right)\left(f+c_{4}\right)}{f^{2}\left(3 f+c_{1}+c_{2}+c_{4}\right)}>1
\end{aligned}
$$

Cut :

summation

$$
V_{c}=\frac{1}{4} L^{2}\left(c_{1}+c_{2}+c_{4}\right)
$$

four point

$$
\begin{aligned}
& V_{c}=\frac{1}{4} L^{2} \frac{\left(c_{1}+c_{2}+c_{4}\right)^{2}}{f+c_{1}+c_{2}+c_{4}} \\
& V_{c}=\frac{1}{6} L^{2}\left\{2 c_{1}+c_{2}+c_{4}-f+\frac{f^{3}}{\left(f+c_{1}\right)\left(f+c_{4}\right)}\right\}
\end{aligned}
$$

stereometric, when divided

by diagonal plane $1-4$

by diagonal plane $2-3$

$$
V_{c}=\frac{1}{6} L^{2}\left\{c_{1}+2 c_{2}+c_{4}-f+\frac{f^{3}}{\left(f+c_{1}\right)\left(f+c_{2}\right)}+\frac{f^{3}}{\left(f+c_{2}\right)\left(f+c_{4}\right)}\right\}
$$

stereometric mean

$$
V_{c}=\frac{1}{12} L^{2}\left\{3 c_{1}+3 c_{2}+3 c_{4}-3 f+f^{3} \frac{3 f+c_{1}+c_{2}+c_{4}}{\left(f+c_{1}\right)\left(f+c_{2}\right)\left(f+c_{4}\right)}\right\}
$$

difference summ. - stereom. $\frac{1}{12} L^{2} f\left\{3-f^{2} \frac{3 f+c_{1}+c_{2}+c_{4}}{\left(f+c_{1}\right)\left(f+c_{2}\right)\left(f+c_{4}\right)}\right\}$

difference f.p. - stereom. $\frac{1}{12} L^{2} f\left\{\frac{3}{f+c_{1}+c_{2}+c_{4}}-f \frac{3 f+c_{1}+c_{2}+c_{4}}{\left(f+c_{1}\right)\left(f+c_{2}\right)\left(f+c_{4}\right)}\right\}$

ratio summ. : stereom.

$$
\begin{aligned}
& \frac{3\left(c_{1}+c_{2}+c_{4}\right)}{3\left(c_{1}+c_{2}+c_{4}\right)-3 f+f^{3} \frac{3 f+c_{1}+c_{2}+c_{4}}{\left(f+c_{1}\right)\left(f+c_{2}\right)\left(f+c_{4}\right)}}>1 \text { or } \\
& \mathrm{f}^{3} \frac{3 f+c_{1}+c_{2}+c_{4}}{\left(f+c_{1}\right)\left(f+c_{2}\right)\left(f+c_{4}\right)}<3 f \text { or } \\
& 3 \frac{\left(f+c_{1}\right)\left(f+c_{2}\right)\left(f+c_{4}\right)}{f^{2}\left(3 f+c_{1}+c_{2}+c_{4}\right)}>1
\end{aligned}
$$


Situ ation c (FIG. 3)

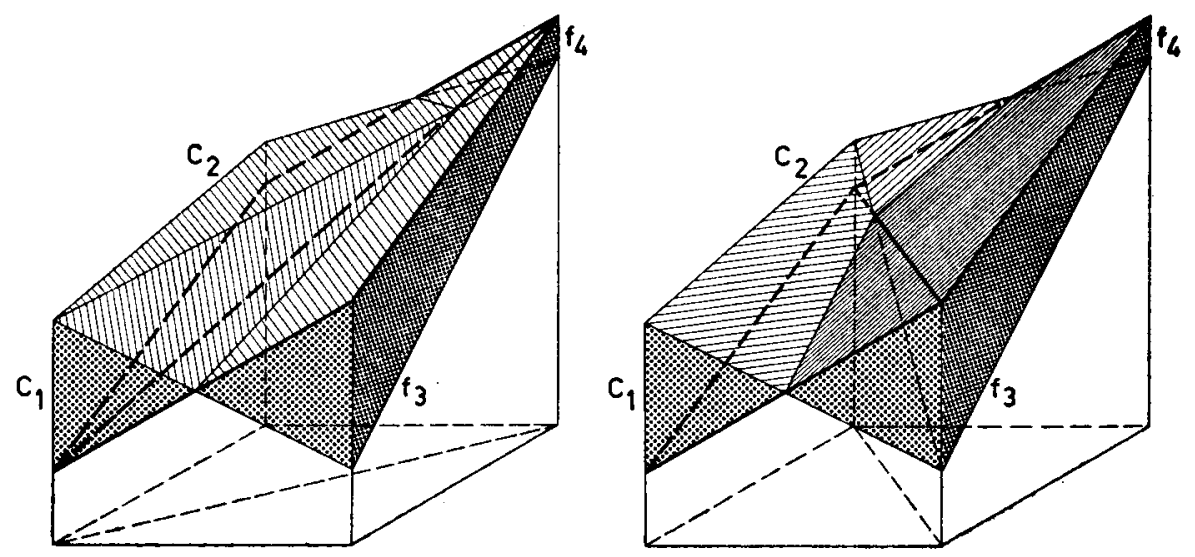

FIGURE 3

For simplicity's sake the notations $Q_{c_{1}}, Q_{c_{2}}, Q_{f_{3}}$ and $Q_{f_{4}}$ are introduced :

$Q_{c_{1}}=\frac{c_{1}^{3}}{\left(c_{1}+f_{3}\right)\left(c_{1}+f_{4}\right)}, Q_{c_{2}}=\frac{c_{2}^{3}}{\left(c_{2}+f_{3}\right)\left(c_{2}+f_{4}\right)}, Q_{f_{3}}=\frac{f_{3}^{3}}{\left(f_{3}+c_{1}\right)\left(f_{3}+c_{2}\right)}$ and $Q f_{4}=\frac{f_{4}^{3}}{\left(f_{4}+c_{1}\right)\left(f_{4}+c_{2}\right)}$

Fill :

summation

$V_{f}=\frac{1}{4} L^{2}\left(f_{3}+f_{4}\right)$

four point

$$
V_{f}=\frac{1}{4} L^{2} \frac{\left(f_{3}+f_{4}\right)^{2}}{\left(c_{1}+c_{2}+f_{3}+f_{4}\right)}
$$

stereometric, when divided by diagonal plane $1-4$

$$
V_{f}=\frac{1}{6} L^{2}\left(-c_{1}+f_{3}+f_{4}+Q_{c_{1}}+Q_{f_{4}}\right)
$$

by diagonal plane $2-3$

$$
V_{f}=\frac{1}{6} L^{2}\left(-c_{2}+f_{3}+f_{4}+Q_{2}+Q_{f_{3}}\right)
$$

stereometric mean

$$
V_{f}=\frac{1}{12} L^{2}\left(-c_{1}-c_{2}+2 f_{3}+2 f_{4}+Q_{c_{1}}+Q_{c_{2}}+Q_{f_{3}}+Q_{f_{4}}\right)
$$

difference summ. - stereom. $\frac{1}{12} L^{2}\left(c_{1}+c_{2}+f_{3}+f_{4}-Q_{c_{1}}-Q_{c_{2}}-Q_{f_{3}}-Q_{f_{4}}\right)$

difference f.p. - stereom. $\frac{1}{12} L^{2}\left\{\frac{\left(c_{1}+c_{2}\right)^{2}+\left(f_{3}+f_{4}\right)^{2}-\left(c_{1}+c_{2}\right)\left(f_{3}+f_{4}\right)}{c_{1}+c_{2}+f_{3}+f_{4}}-Q_{c_{1}}-Q_{c_{2}}-Q_{f_{3}}-Q_{f_{4}}\right\}$

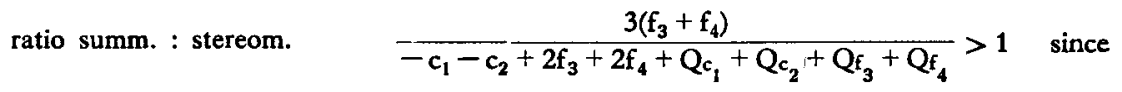

$$
c_{1}+c_{2}+f_{3}+f_{4}>Q_{c_{1}}+Q_{c_{2}}+Q_{3}+Q_{4}
$$


Cut :

summation

four point

stereometric, when divided by diagonal plane $1-4$

by diagonal plane $2-3$

stereometric mean

$$
\mathrm{V}_{\mathrm{c}}=\frac{1}{4} \mathrm{~L}^{2}\left(\mathrm{c}_{1}+\mathrm{c}_{2}\right)
$$

$$
\mathrm{V}_{\mathrm{c}}=\frac{1}{4} \mathrm{~L}^{2} \frac{\left(\mathrm{c}_{1}+\mathrm{c}_{2}\right)^{2}}{\left(\mathrm{c}_{1}+\mathrm{c}_{2}+\mathrm{f}_{3}+\mathrm{f}_{4}\right)}
$$

$$
\mathrm{V}_{\mathrm{c}}=\frac{1}{6} \mathrm{~L}^{2}\left(\mathrm{c}_{1}+\mathrm{c}_{2}-\mathrm{f}_{4}+\mathrm{Q}_{\mathrm{c}_{1}}+\mathrm{Qf}_{4}\right)
$$

$$
\mathrm{V}_{\mathrm{c}}=\frac{1}{6} \mathrm{~L}^{2}\left(\mathrm{c}_{1}+\mathrm{c}_{2}-\mathrm{f}_{3}+\mathrm{Qc}_{2}+\mathrm{Qf}_{3}\right)
$$

$$
\mathrm{V}_{\mathrm{c}}=\frac{1}{12} \mathrm{~L}^{2}\left(2 \mathrm{c}_{1}+2 \mathrm{c}_{2}-\mathrm{f}_{3}-\mathrm{f}_{4}+\mathrm{Q}_{\mathrm{c}_{1}}+\mathrm{Q}_{\mathrm{c}_{2}}+\mathrm{Qf}_{3}+\mathrm{Qf}_{4}\right)
$$

difference summ. - stereom. $\frac{1}{12} L^{2}\left(c_{1}+c_{2}+f_{3}+f_{4}-Q_{c_{1}}-Q_{c_{2}}-Q f_{3}-Q_{f_{4}}\right)$

difference f.p. - stereom. $\frac{1}{12} L^{2}\left\{\frac{\left(c_{1}+c_{2}\right)^{2}+\left(f_{3}+f_{4}\right)^{2}-\left(c_{1}+c_{2}\right)\left(f_{3}+f_{4}\right)}{c_{1}+c_{2}+f_{3}+f_{4}}-Q_{c_{1}}-Q_{c_{2}}-Q_{f_{3}}-Q_{1}\right\}$ ratio summ. : stereom. $\quad \frac{3\left(c_{1}+c_{2}\right)}{2 c_{1}+2 c_{2}-f_{3}-f_{4}+Q c_{1}+Q c_{2}+Q f_{3}}+Q_{f_{4}}>1$ since $c_{1}+c_{2}+f_{3}+f_{4}>Q_{c_{1}}+Q_{c_{2}}+Q_{f_{3}}+Q_{f_{4}}$

Situation d (FIG. 4)
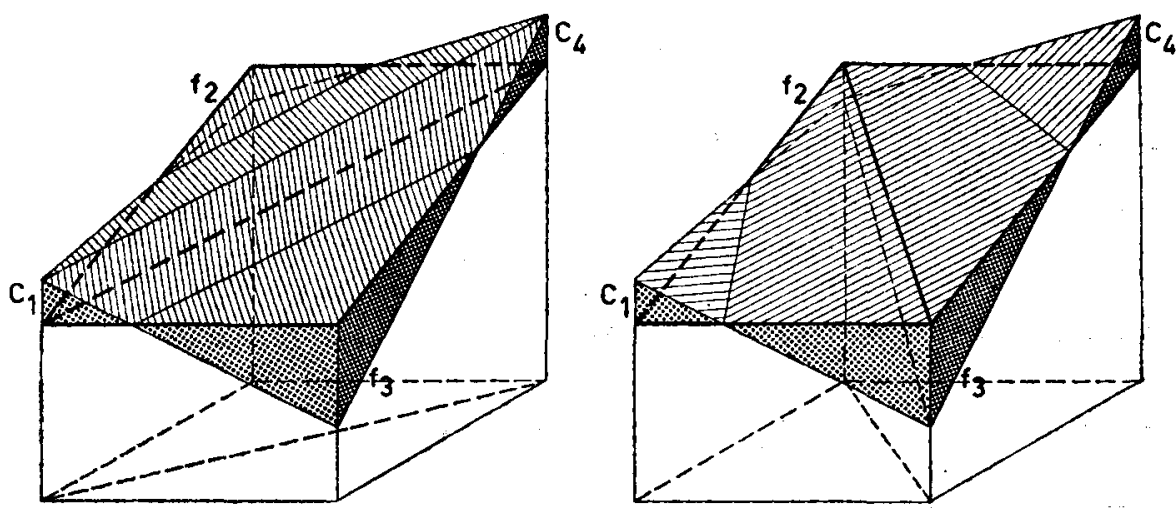

Figure 4

Fill :

summation

four point

stereometric, when divided by diagonal plane $1-4$
$\mathrm{V}_{\mathrm{f}}=\frac{1}{4} \mathrm{~L}^{2}\left(\mathrm{f}_{2}+\mathrm{f}_{3}\right)$

$$
V_{f}=\frac{1}{4} L^{2} \frac{\left(f_{2}+f_{3}\right)^{2}}{\left(c_{1}+c_{4}+f_{2}+f_{3}\right)}
$$

$\mathrm{V}_{\mathrm{f}}=\frac{1}{6} \mathrm{~L}^{2}\left(\mathrm{Qf}_{2}+\mathrm{Qf}_{3}\right)$ 
by diagonal plane $2-3$

stereometric mean

$$
V_{f}=\frac{1}{6} L^{2}\left(-c_{1}-c_{4}+2 f_{2}+2 f_{3}+Q_{c_{1}}+Q_{c_{4}}\right)
$$$$
\frac{1}{12} L^{2}\left(-c_{1}-c_{4}+2 f_{2}+2 f_{3}+Q_{c_{1}}+Q_{c_{4}}+Q_{f_{2}}+Q_{f_{3}}\right)
$$

difference summ. - stereom. $\frac{1}{12} L^{2}\left(c_{1}+c_{4}+f_{2}+f_{3}-Q_{c_{1}}-Q_{c_{4}}-Q_{f_{2}}-Q_{f_{3}}\right)$

difference f.p. - stereom. $\frac{1}{12} L^{2}\left\{\frac{\left(c_{t}+c_{4}\right)^{2}\left(f_{2}+f_{3}\right)^{2}-\left(c_{1}+c_{4}\right)\left(f_{2}+f_{3}\right)}{c_{1}+c_{4}+f_{2}+f_{3}}-Q_{c_{1}}-Q_{c_{4}}-Q_{f_{2}}-Q_{f_{3}}\right\}$

ratio summ. : stereom.

$$
\begin{aligned}
& \frac{3\left(f_{2}+f_{3}\right)}{-c_{1}-c_{4}+2 f_{2}+2 f_{3}+Q_{c_{1}}+Q_{c_{4}}+Q_{f_{2}}+Q_{f_{3}}}>1 \text { since } \\
& c_{1}+c_{4}+f_{2}+f_{3}>Q_{c_{1}}+Q_{c_{4}}+Q_{f_{2}}+Q_{f_{3}}
\end{aligned}
$$

Cut :

summation

$$
\mathrm{V}_{\mathrm{c}}=\frac{1}{4} \mathrm{~L}^{2}\left(\mathrm{c}_{1}+\mathrm{c}_{4}\right)
$$

four point

$$
V_{c}=\frac{1}{4} L^{2} \frac{\left(c_{1}+c_{4}\right)^{2}}{c_{1}+c_{4}+f_{2}+f_{3}}
$$

stereometric, when divided by diagonal plane $1-4$

$$
V_{c}=\frac{1}{6} L^{2}\left(2 c_{1}+2 c_{4}-f_{2}-f_{3}+Q_{f_{2}}+Q_{f_{3}}\right)
$$

by diagonal plane $2-3$

$$
\mathrm{V}_{\mathrm{c}}=\frac{1}{6} \mathrm{~L}^{2}\left(\mathrm{Q}_{\mathrm{c}_{1}}+\mathrm{Q}_{\mathrm{c}_{4}}\right)
$$

$$
\frac{1}{12} L^{2}\left(2 c_{1}+2 c_{4}-f_{2}-f_{3}+Q c_{t}+Q_{c_{4}}+Q_{f_{2}}+Q \varepsilon_{3}\right)
$$

difference summ. - stereom. $\frac{1}{12} L^{2}\left(c_{1}+c_{4}+f_{2}+f_{3}-Q_{c_{1}}-Q_{c_{4}}-Q_{f_{2}}-Q_{f_{3}}\right)$

difference f.p. - stereom. $\frac{1}{12} L^{2}\left\{\frac{\left(c_{1}+c_{4}\right)^{2}\left(f_{2}+f_{3}\right)^{2}-\left(c_{1}+c_{4}\right)\left(f_{2}+f_{3}\right)}{c_{1}+c_{4}+f_{2}+f_{3}}-Q_{c_{1}}-Q_{c_{4}}-Q_{f_{2}}-Q_{f_{3}}\right\}$

ratio summ. : stereom.

$$
\begin{aligned}
& \frac{3\left(c_{1}+c_{4}\right)}{2 c_{1}+2 c_{4}-f_{2}-f_{3}+Q_{c_{1}}+Q_{c_{4}}+Q_{f_{2}}+Q_{f_{3}}}>1 \quad \text { since } \\
& c_{1}+c_{4}+f_{2}+f_{3}>Q_{c_{1}}+Q_{c_{4}}+Q_{f_{2}}+Q_{3}
\end{aligned}
$$

The results of the calculations show the following:

a. For each situation, the differences between the results of summation and four-point calculations on the one hand and of the stereometric calculations on the other are equal for the volumes of cut and fill.

b. The ratio of the results of summation and stereometric calculation is always greater than one (the ratio of the results of the four-point and the stereometric calculation is variable, i.e. sometimes bigger, sometimes smaller than one, and has, therefore, not been worked out).

c. The stereometric formulae are complicated.

Consequently, the following conclusions occur :

a. Each of the three calculation methods is suitable for the calculation of earthwork balances, since the difference between the approximate summation and fourpoint results on the one hand and the exact stereometric results on the other are equally great for cut and fill in those grid squares, where cut changes to fill, whereas the results of the three calculation methods are identical for grid squares with all four corners in cut or in fill, as demonstrated before. 
b. Since the ratio of the results of the summation and the stereometric methods is always greater than one, summation will give volumes which are too great, the more so when grid squares, where cut changes to fill, occur frequently.

The four-point method will give results which are too great at one time and too small at another.

c. The stereometric formulae are too complicated for practical use. Moreover, each grid square, where cut changes to fill has to be judged individually in order to determine which formula should be applied.

In FIG. 9, a number of cross sections through grid squares are drawn showing a two-dimensional representation of the actual volumes of cut and fill in comparison to the volumes calculated according to the three methods. This figure will be discussed afterwards. However, the exaggerated volumes of cut and fill as calculated by summation (rectangular areas) stand out clearly in nearly all cases, when compared with the actual volumes, and in all cases when compared with the volumes, calculated according to the four-point and stereometric methods (triangular areas).

In FIG. 5, a situation is represented with two adjacent grid points in fill and the other two in cut. Moreover, both the present and the future surfaces are planes.

The volumes of cut and fill are truncated three-sided pyramids. Application of the prismoidal formula $\left(V=\frac{1}{6} L\left(a_{1}+4 a_{m}+a_{2}\right) ; a_{1}\right.$ and $a_{2}=$ parallel end areas, $a_{\mathrm{m}}=$ area in middle section parallel to end planes) allows an exact stereometric calculation of these volumes.

The volumes are only approximately correct when calculated according to the formula $\mathrm{V}=\mathrm{L} \times \mathrm{a}_{\mathrm{m}}$. This formula holds good for a three-sided rectangular prism. Consequently, this method of calculation is only correct if the two cut values on the one hand and the two fill values on the other are mutually equal.

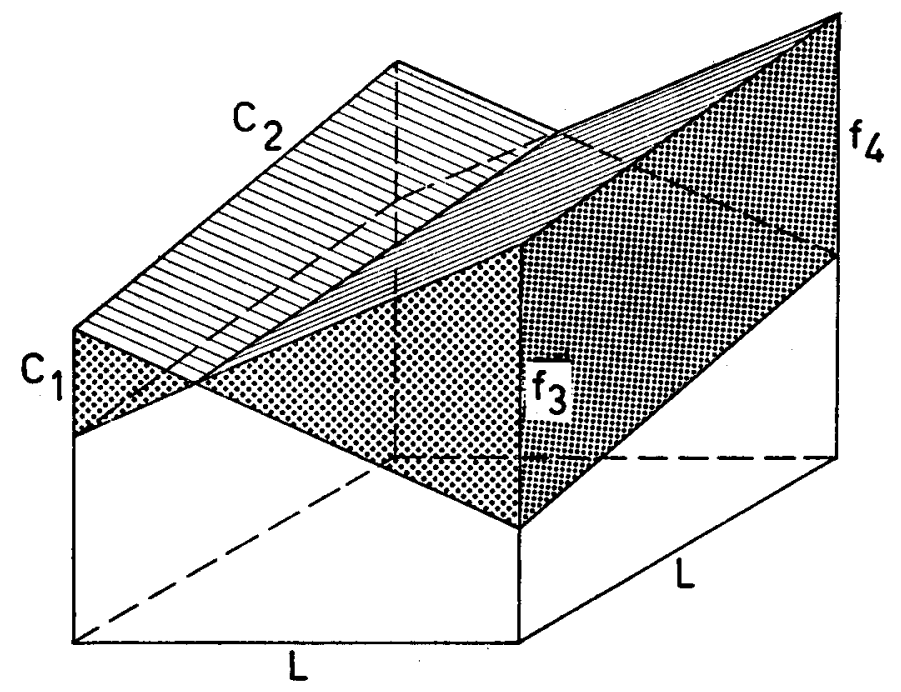

Figure 5 
Now, considering the volume of cut for instance,

$$
\begin{aligned}
& a_{1}=\frac{c_{1}}{c_{1}+f_{3}} L \times \frac{c_{1}}{2}=\frac{L}{2} \times \frac{c_{1}^{2}}{c_{1}+f_{3}} \\
& a_{2}=\frac{c_{2}}{c_{2}+f_{4}} L \times \frac{c_{2}}{2}=\frac{L}{2} \times \frac{c_{2}^{2}}{c_{2}+f_{4}} \\
& a_{m}=\frac{c_{1}+c_{2}}{c_{1}+c_{2}+f_{3}+f_{4}} L \times \frac{c_{1}+c_{2}}{2 \times \frac{L}{2}}=\frac{L}{4} \times \frac{\left(c_{1}+c_{2}\right)^{2}}{c_{1}+c_{2}+f_{3}+f_{4}}
\end{aligned}
$$

So, the volume of cut according to the prismoidal formula amounts to:

$$
\mathrm{V}_{\mathrm{c}_{\mathrm{pr}}}=\frac{\mathrm{L}^{2}}{12}\left\{\frac{\mathrm{c}_{1}{ }^{2}}{\mathrm{c}_{1}+\mathrm{f}_{3}}+\frac{\mathrm{c}_{2}{ }^{2}}{\mathrm{c}_{2}+\mathrm{f}_{4}}+\frac{2\left(\mathrm{c}_{1}+\mathrm{c}_{2}\right)^{2}}{\mathrm{c}_{1}+\mathrm{c}_{2}+\mathrm{f}_{3}+\mathrm{f}_{4}}\right\}
$$

and according to the approximate formula to:

$$
V_{c_{f p}}=\frac{L^{2}}{4} \times \frac{\left(c_{1}+c_{2}\right)^{2}}{c_{1}+c_{2}+f_{3}+f_{4}}=\frac{L^{2}}{4} \frac{H_{c}{ }^{2}}{H_{c}+H_{f}}
$$

It appears that the approximate calculation method leads to the four-point formula. The condition ensuring exact results when applying the four-point formula is also derived by assuming the prismoidal formula to be equal to the four-point formula after substitution of the magnitudes represented in FIG. 5.

The equation obtained in this way appears to become an equality when $\frac{c_{1}}{c_{2}}=\frac{f_{3}}{f_{4}}$.

It is evident that under the conditions represented in FIG. 5 this postulate is only fulfilled when $c_{1}=c_{2}$ and $f_{3}=f_{4}$. Moreover, the present and future land surfaces should be planes. Generally, the error introduced by applying the four-point method is relatively small in grid squares with two adjacent points in cut and the other two in fill. It needs no further explanation that when two points are in cut and the other two in fill at diagonal corners or when one point out of four is in cut and the others in fill, or the reverse, bigger errors are introduced.

\subsection{Elimination of the mathematicalerror ingrid squares} where cut changes to fill

It has been demonstrated that it is possible to arrive at stereometric formulae permitting the exact calculation of earth-work volumes per grid square for all situations, but that these formulae are too complicated for practical application.

Since the summation method is by far the simplest one and equally suitable for the calculation of earth-work balances as any other method, it is interesting to investigate the possibility as to whether an exact stereometric result could be obtained by introducing a relatively simple correction procedure into the summation method.

It will be demonstrated that this is indeed possible and that this procedure lends itself to the development of tabular aids and nomographs.

A simpler relationship between volumes of earth movement calculated according to the summation and the stereometric methods is obtained when these calculations are restricted to diagonally divided half grid squares. 
The conceivable combinations of cut and fill are now restricted to:

a. two points in cut, one point in fill (FIG. 6),

b. two points in fill, one point in cut.

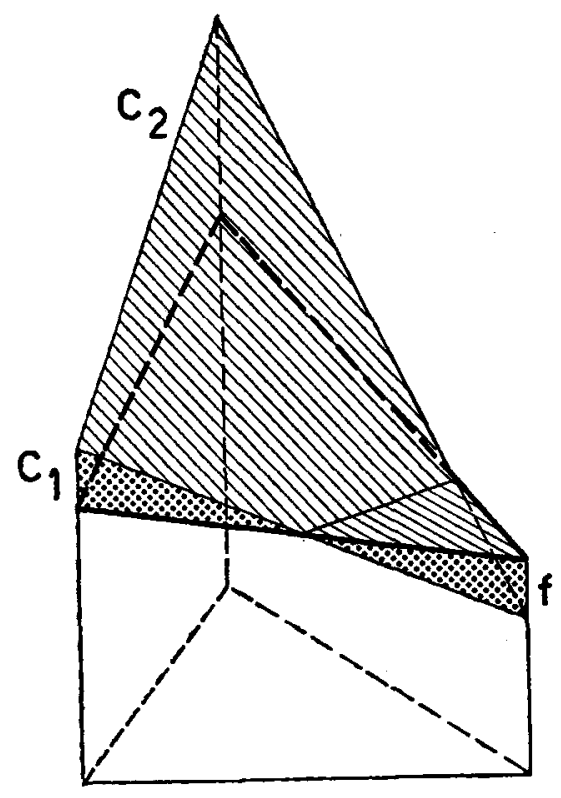

Figure 6

Fill :

$$
\begin{array}{lcl}
\text { summation } & V_{f}=\frac{1}{6} L^{2} f \\
\text { stereometric } & V_{f}=\frac{1}{6} L^{2} Q_{f} \\
\text { difference summ. - stereom. } & \frac{1}{6} L^{2}\left(f-Q_{f}\right) \\
\text { ratio } & \frac{\left(f+c_{1}\right)\left(f+c_{2}\right)}{f^{2}}>1
\end{array}
$$

(the notation $Q_{f}$ has the same meaning as when considering the full grid squares, viz. $\left.Q_{f}=\frac{f 3}{\left(f+c_{1}\right)\left(f+c_{2}\right)}\right)$.

Cut :

$$
\begin{array}{ll}
\text { summation } & V_{c}=\frac{1}{6} L^{2}\left(c_{1}+c_{2}\right) \\
\text { stereometric } & V_{c}=\frac{1}{6} L^{2}\left(c_{1}+c_{2}-f+Q_{f}\right) \\
\text { difference summ. - stereom. } & \frac{1}{6} L^{2}\left(f-Q_{f}\right)
\end{array}
$$


ratio

$$
\frac{c_{1}+c_{2}}{c_{1}+c_{2}-f+Q f}>1 \text { since } f>Q f
$$

Situation $b$ is analagous to $a$. By changing the meaning of the two triangular planes representing the present and the future surface as well as the letter $c$ and $f$, the same FIG. 6 holds good for situation $b$ and comparison of the two calculations gives :

difference summ. - stereom. $\quad \frac{1}{6} L^{2}\left(c-Q_{c}\right)$

ratio

$$
\frac{f_{1}+f_{2}}{f_{1}+f_{2}-c+Q_{c}}>1 \text { since } c>Q_{c}
$$

The results obtained in this way lead to conclusions similar to those obtained from the calculations on full grid squares. However, the relationship between the results of summation and of stereometric calculation is much simpler and permits a relatively easy correction of the former. If we distinguish between double similar earth movements and a single opposite earth movement (occurring in two and one corner of half a grid square respectively), the following correction, to be deducted from the volume obtained by summation, holds good for both situations :

$$
\begin{aligned}
\Delta V & =\frac{L^{2}}{6}\left\{E_{s}-\frac{E_{s}^{3}}{\left(E_{s}+E_{d_{1}}\right)\left(E_{s}+E_{d_{2}}\right)}\right\}=\frac{L^{2}}{6} d \\
\Delta V & =\text { volume to be deducted from result of summation } \\
\mathbf{L} & =\text { grid spacing } \\
\mathbf{E}_{\mathrm{s}} & =\text { single earth movement, occurring in one corner of half a grid square } \\
\mathbf{E}_{\mathrm{d}} & =\text { double earth movement, occurring in two corners of half a grid square } \\
\mathbf{d} & =\text { deduction factor. }
\end{aligned}
$$

The step-by-step procedure to correct summation results is now as follows :

a. Mark all grid squares, where cut changes to fill by drawing the diagonals (including squares traversed by the boundary of the plot to be levelled);

b. Calculate the deduction factor for each marked half grid square, first for the halves on both sides of diagonals running from the upper left to the lower right;

c. Reduce the deduction factors of grid squares, lying partly outside the plot to be levelled, proportionally (weight w);

d. Add all deduction factors obtained in this way : [ $\left.\mathrm{w}_{1} \mathrm{~d}_{1}\right]=\mathrm{D}_{1}$, the first total deduction factor;

e. Repeat the steps $b$ through $d$ for the marked half grid squares on both sides of diagonals running from the upper right to the lower left. Thus $\mathrm{D}_{2}$, the second total deduction factor is obtained;

f. Determine the average total deduction factor as follows:

$$
\overline{\mathbf{D}}=\frac{\mathbf{D}_{1}+\mathbf{D}_{2}}{12}
$$

$\mathrm{L}^{2} \overline{\mathrm{D}}=\Delta \mathrm{V}$, the total volume to be deducted. It is simpler not to calculate this volume but instead:

g. Determine $C-\bar{D}$ and $F-\bar{D}$ (C and $F$ being the totals of all cut and fill values obtained by summation):

h. Determine $L^{2}(C-\bar{D})$ and $L^{2}(F-\bar{D})$ being the total volumes of cut and fill, respectively, calculated stereometically. 
Calculation of the deduction factor $d$ is much facillitated by tabular aids or nomographs.

A part of a table, drawn up for this purpose, is represented below.

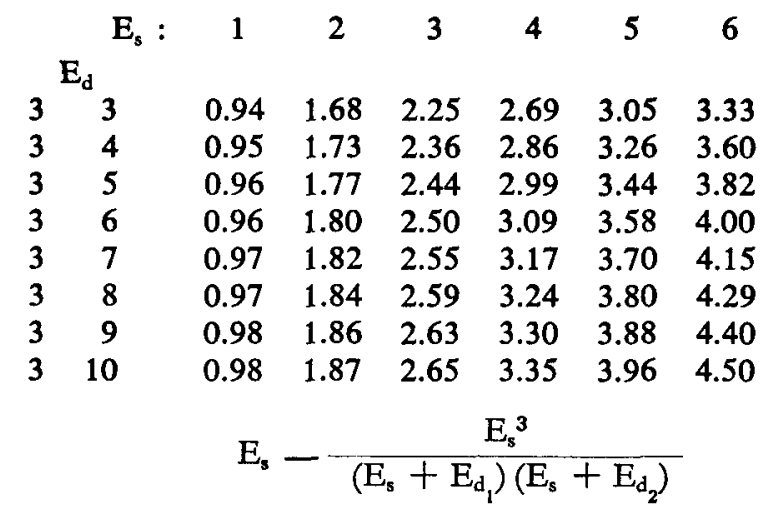

With the aid of nomographs, only the term $\frac{E_{s}^{3}}{\left(E_{s}+E_{d_{1}}\right)\left(E_{s}+E_{d_{2}}\right)}$ i.e. the sub-
strahend, is determined.

Two types of nomographs have been drawn up, viz. an intersection diagram and an alignment diagram. The intersection diagram allows a rapid determination of the substrahend but has the drawback that a separate scale has to be used involving the risk of a difference in shrinkage of the nomograph and the scale paper, although so far this drawback has not caused noticeable difficulties in practice.

The use of alignment diagrams requires the determination of auxiliary points, is, therefore, somewhat less rapid and may lead to minor inaccuracies. Further practical experience will show which method is preferable.

It is possible to avoid the calculation of two series of deduction factors by changing the grid system from a rectangular to a triangular one. Practical experience will have to show how far such a change may constitute a problem in field work.

It is also possible to introduce a correction into the summation method in order to obtain the same results as when applying the four point-method.

According to the summation method the volumes of cut and fill per grid square amount to:

$$
V_{c}=\frac{L^{2}}{4} H_{c} \text { and } V_{f}=\frac{L^{2}}{4} H_{f}
$$

The same volumes calculated with the four-point method amount to:

$$
\mathrm{V}_{\mathrm{c}}=\frac{\mathrm{L}^{2}}{4} \times \frac{\mathrm{H}_{\mathrm{c}}{ }^{2}}{\mathrm{H}_{\mathrm{c}}+\mathrm{H}_{\mathrm{f}}} \text { and } \mathrm{V}_{f}=\frac{\mathrm{L}^{2}}{4} \times \frac{\mathrm{H}_{\mathrm{f}}{ }^{2}}{\mathrm{H}_{\mathrm{c}}+\mathrm{H}_{\mathrm{f}}}
$$

Substraction of the four-point volumes from the summation volumes gives :

$$
\Delta V=\frac{L^{2}}{4} \times \frac{H_{c} H_{f}}{H_{c}+H_{f}} \text { for the volumes of both cut and fill. }
$$

In this way, it is possible to correct the results of summation by calculating the $\Delta V$-values for the grid squares where cut changes to fill only.

When using tabular aids for the determination of $\frac{\mathrm{H}_{c} \mathrm{H}_{f}}{\mathrm{H}_{\mathrm{c}}+\mathrm{H}_{\mathrm{f}}}$ it is often simpler to correct sum- 
mation results than to go through a complete four-point calculation. On the other hand the application of a correction method to obtain fairly exact results seems to be less attractive than the application of a correction method giving mathematically exact results. The latter is achieved when applying a stereometric correction.

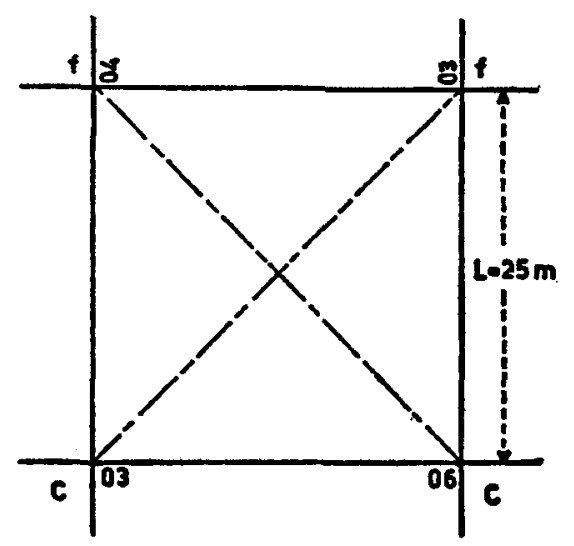

FiguRe 7

In FIG. 7 a grid square is represented where cut changes to fill, serving as an example of the calculations described before.

summation :

$$
\begin{aligned}
& V_{c}=\frac{1}{4} \frac{L^{2}}{100} \times 9 \\
& V_{f}=\frac{1}{4} \frac{L^{2}}{100} \times 7
\end{aligned}
$$

stereometric (according to the formulae pertaining to FIG. 3) :

$$
\begin{aligned}
& V_{c}=\frac{1}{4} \frac{L^{2}}{100} \times 5.15 \\
& V_{f}=\frac{1}{4} \frac{L^{2}}{100} \times 3.15
\end{aligned}
$$

stereometric correction :

$$
\Delta V_{s t}=\frac{1}{4} \frac{L^{2}}{100} \times 3.85
$$

four point :

$$
\begin{aligned}
& V_{c}=\frac{1}{4} \frac{L^{2}}{100} \times 5.06 \\
& V_{f}=\frac{1}{4} \frac{L^{2}}{100} \times 3.06
\end{aligned}
$$

four-point correction : $\quad \Delta \mathrm{V}_{\mathrm{f}}=\frac{1}{4} \frac{\mathrm{L}^{2}}{100} \times 3.94$ 
It appears from these figures that, in this example, the volumes calculated after the summation method are appreciably greater and calculated after the four-point method slightly smaller than the stereometric volumes.

\subsection{The evaluation of volumes of cut and fillingridsquares traversed by the plot's boundaries}

It has been demonstrated that for the calculation of earth-work balances it is immaterial which of the three methods of calculation under consideration is applied. However, when doing so in practice, considerably different balances are calculated by the summation method on the one hand and by the four-point and stereometric methods on the other.

It will be demonstrated that, when applying the above-mentioned methods, the volumes of cut and fill in the grid squares traversed by the plot's boundaries are evaluated in different ways resulting in different earth-work balances.

Since the variability of the volumes of cut and fill in grid squares traversed by the plot's boundaries is unlimited, only a statistical calculation will give a reasonable approximation of the reality without being too time-consuming. This is usually done by multiplying the volumes calculated for the full square with the fraction of the square lying inside the plot.

When applying the summation method the grid points are considered to lie in the centres of the grid squares. By reducing the volumes of cut and fill of a grid traversed by the boundary in proportion to the area lying inside the plot, these volumes receive a weight smaller than 1; the volumes of grids lying completely inside the plot have the weight 1. So, the volumes of cut and fill per grid square are considered to depend on the grid-point value of the centre only and not to be influenced by the values of the adjoining grid points.

When applying the four-point method, grid squares with grid points in the four corners are considered. When calculating the volumes of each grid square, each grid point belonging to a square lying completely inside the plot, is counted 4 times and, therefore, receives the weight 4 . Should the plot's boundaries coincide with grid lines, the grid points lying on the boundary would receive the weight 2 and a grid point lying at a corner of the plot would get the weight 1 . Since the total is ultimately multiplied by $\frac{1}{4}$, the final weights amount to $1, \frac{1}{2}$ and $\frac{1}{4}$ respectively. So far, the same would occur when applying the summation method. However, when grid squares are traversed by the plot's boundaries, the influence of grid points lying outside the plot, even at a distance greater than $0.5 \mathrm{~L}$, is accounted for as well.

If, for instance, a grid square lies for $40 \%$ only inside the area, the two grid points outside the area are given the final weight $\frac{2 \times 0.4}{4}=0.2$, whereas the two grid points inside the area get the final weight $\frac{2 \times 0.4+2 \times 1}{4}=0.7$.

In this respect the four-point method and any other method considering the grid points to lie at the corners of the grid squares is superior to the summation method. There is, however, no reason why the attachment of weights, as done for the fourpoint method, should not be applied in the same way to the summation method. If then, a stereometric correction is applied afterwards, a good approach to the reality is made. 
The effect of the two methods of calculating volumes of squares traversed by a boundary is demonstrated best in a plot where a relatively great number of such grid squares occur.

The following example will serve this purpose (FIG. 8):

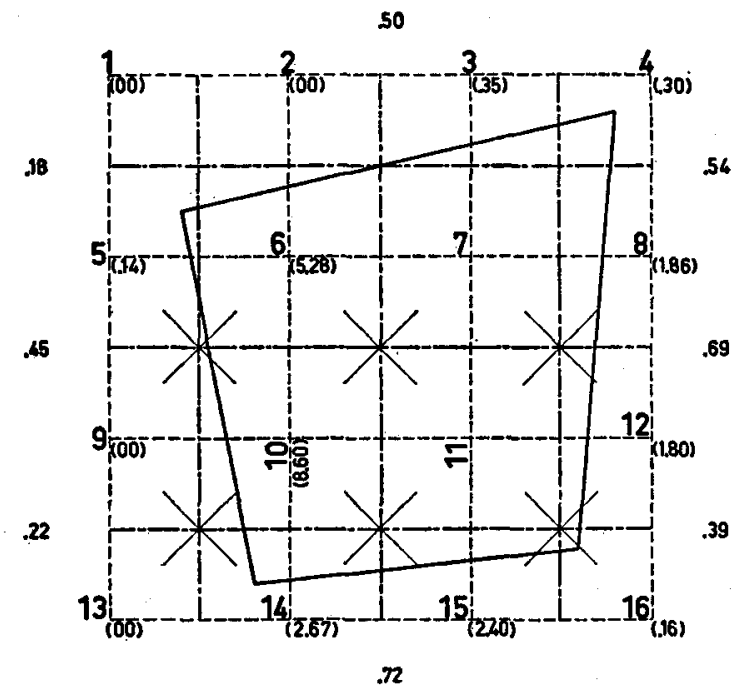

Figure 8

A plot with a local depression is covered by two grid nets, one with the grid points in the centre of the squares, the other with the grid points in the corners of the squares. The fractions of the squares lying inside the plot's boundaries are indicated along the edges of the grid net for the latter squares. The fraction of the squares with the grid point in the centre has been multiplied by the grid-point values; the result is represented as a reduced grid-point value between brackets. Negative gridpoint values (fill) are indicated by turning the figures $90^{\circ}$.

summation, usual procedure




summation with improved weights :

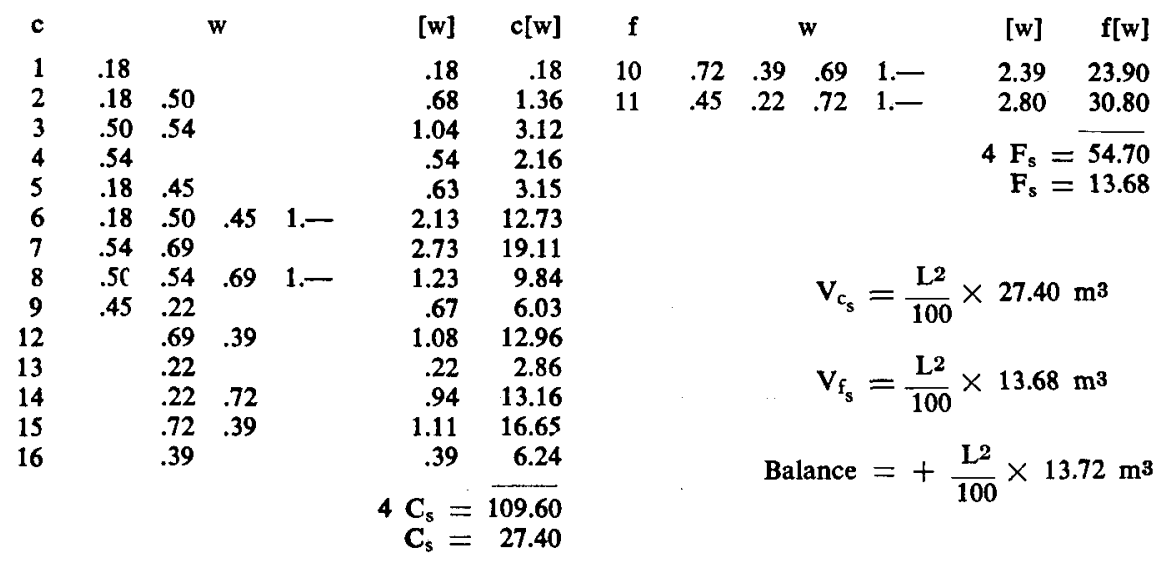

four-point correction :



$$
\begin{aligned}
& 4 D_{f}=\overline{30.33} \\
& \mathrm{D}_{\mathrm{f}}=7.58 \\
& \Delta \mathrm{V}_{\mathrm{f}}=\frac{\mathrm{L}^{2}}{100} \times \mathrm{D}_{\mathrm{f}}=\frac{\mathrm{L}^{2}}{100} \times 7.58 \\
& \begin{array}{l}
V_{c_{f}}=\frac{L 2}{100}\left(V_{c_{s}}-D_{f}\right)=\frac{L 2}{100} \times(27.40-7.58)=\frac{L 2}{100} \times 19.82 \\
V_{f_{f}}=\frac{L 2}{100}\left(V_{f_{s}}-D_{f}\right)=\frac{L 2}{100} \times(13.68-7.58)=\frac{L 2}{100} \times 6.10
\end{array}
\end{aligned}
$$

stereometric correction :

diagonal division: upper right - lower left

$\begin{array}{rrrrrr}\mathrm{E}_{s} & \mathrm{E}_{\mathrm{d}_{1}} & \mathrm{E}_{\mathrm{d}_{2}} & \mathrm{~d} & \mathrm{w} & \mathrm{dw} \\ 10 & 6 & 9 & \mathbf{6 . 7 9} & .45 & 3.06 \\ 10 & 6 & 7 & 6.33 & 1 .- & 6.33 \\ 7 & 10 & 11 & 5.88 & 1 . \overline{5} & 5.88 \\ 11 & 7 & 8 & 7.11 & .69 & 4.90 \\ 11 & 8 & 12 & 7.95 & .69 & 5.49 \\ 10 & 9 & 13 & 7.71 & .22 & 1.70 \\ 10 & 13 & 14 & 8.20 & .22 & 1.80 \\ 14 & 10 & 11 & 9.42 & .72 & 6.78 \\ 11 & 14 & 15 & 8.95 & .72 & 6.44 \\ 11 & 12 & 15 & \mathbf{8 . 7 9} & .39 & 3.43 \\ & & & & \mathrm{D}_{\text {st }_{1}}=\frac{44.56}{}\end{array}$

diagonal division: upper left - lower right 


$$
\begin{aligned}
\overline{\mathrm{D}}_{\mathrm{st}} & =\frac{44.56+45.81}{12}=7.53 \\
\Delta \mathrm{V}_{\mathrm{st}} & =\frac{\mathrm{L} 2}{100} \times \overline{\mathrm{D}}_{\mathrm{st}}=\frac{\mathrm{L} 2}{100} \times 7.53 \\
\mathrm{~V}_{\mathrm{st}} & =\frac{\mathrm{L}^{2}}{100}\left(\mathrm{~V}_{\mathrm{c}_{\mathrm{s}}}-\overline{\mathrm{D}}_{\mathrm{st}}\right)=\frac{\mathrm{L} 2}{100}(27.40-7.53)=\frac{\mathrm{L}^{2}}{100} \times 19.87 \\
\mathrm{~V}_{\mathrm{f}_{\mathrm{st}}} & =\frac{\mathrm{L}^{2}}{100}\left(\mathrm{~V}_{\mathrm{f}_{\mathrm{s}}}-\overline{\mathrm{D}}_{\mathrm{st}}\right)=\frac{\mathrm{L}^{2}}{100}(13.68-7.53)=\frac{\mathrm{L} 2}{100} \times 6.15
\end{aligned}
$$

Summary of the results :

$$
\begin{array}{rrc}
\frac{100}{\mathbf{L}^{2}} \times \text { cut } & \frac{100}{\mathbf{L}^{2}} \times \text { fill } & \frac{100}{\mathbf{L}^{2}} \times \text { balance } \\
17.21 & 19.60 & +2.36 \\
27.40 & 13.68 & +13.72 \\
19.82 & 6.10 & +13.72 \\
19.87 & 6.15 & +13.72
\end{array}
$$

summation

summation with improved weights

four point

stereometric

The four-point and stereometric figures are the result of corrected summation values. However, if the four-point and stereometric calculations are made in full, the result is the same.

The above figures confirm the thesis that each of the three calculation methods gives the same balance, provided that in each case the grid points are considered to be lying in the corners of the grid squares.

There is a marked difference between summation results with and without improved weights. This was to be anticipated because the example was drawn up in such a way that relatively many grid squares were traversed by the plot's boundaries to obtain a clear picture of the influence of such a situation. In practice such a case will seldom or never be encountered.

However, the phenomenon demonstrated in this way holds good in practice too.

\subsection{Some practical examples}

In the following, the correction of summation calculations will be demonstrated by means of practical examples derived from earth-work calculations made by the International Land Development Consultants Ltd. for irrigation purposes in the Middle East.

The calculations of the first plot (FIG. 9) are given in full. The results of the fourpoint calculation is obtained in two ways: by the complete calculation and by correcting the summation values. The small difference in the results has to be ascribed to the rounding off of figures.

To demonstrate the simplification which is obtained when data of a triangular net are treated, the original grid net is transformed into a triangular one by interpolation (FIG. 10). This example does not claim a high accuracy, because the triangles are isosceles instead of equilateral, adversely influencing the apportioning of weights, and because the interpolation tends to smooth out extreme values of survey data. As a result, the volumes calculated with the aid of the triangular net are somewhat smaller than those calculated with the aid of a net of squares.

In the remaining examples, FIGS. $11,12,13$, only the results of the various calculation methods are given for comparison. Both summation methods have been applied. Only the improved weights are represented in the figures. 


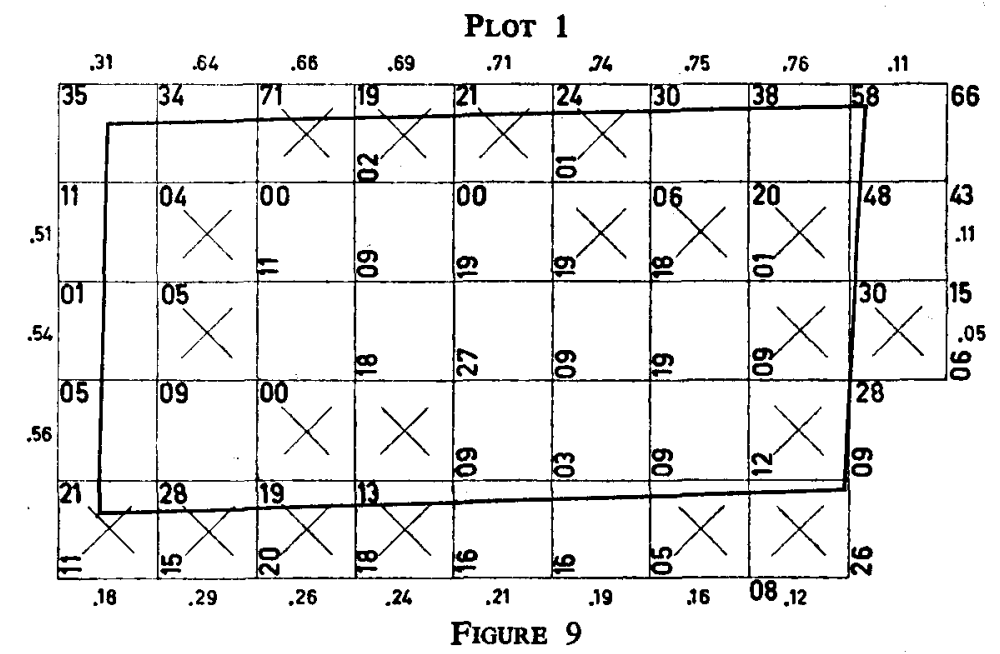

Plot 1. 口-net (FIG. 9)

$$
\begin{aligned}
& \text { summation } \\
& \begin{array}{ccr}
c & \text { w } & \multicolumn{1}{c}{\text { cw }} \\
34 & .145 & 4.93 \\
71 & .150 & 10.65 \\
19 & .175 & 3.32 \\
21 & .200 & 4.20 \\
24 & .225 & 5.40 \\
30 & .245 & 7.35 \\
38 & .225 & 9.70 \\
58 & .190 & 11.02 \\
& & 4 .- \\
& & 6 .-
\end{array} \\
& 48 \quad .625 \quad 30 .- \\
& \begin{array}{llr}
30 & .575 & 5.7 .25
\end{array} \\
& \begin{array}{lll}
28 & .535 & 14.99
\end{array} \\
& \begin{array}{rrr}
21 & .048 & 1.01 \\
28 & .785 & 21.96 \\
1 & .775 & 14.73
\end{array} \\
& \begin{array}{lll}
19 & .775 & 14.73
\end{array} \\
& \begin{array}{lll}
13 & .750 & 9.75
\end{array} \\
& C=\overline{210.26} \mathrm{~cm} \quad F=\overline{187.39} \mathrm{~cm} \\
& \mathrm{C}=210.26 \mathrm{~cm} \quad \mathrm{~F}=187.39 \mathrm{~cm} \\
& \frac{\mathrm{L}^{2}}{100}=6.25 \\
& \text { Balance }=\frac{\mathrm{L}^{2}}{100}(\mathrm{C}-\mathrm{F})=142.94 \mathrm{~m}^{3}
\end{aligned}
$$

\begin{tabular}{|c|c|c|c|}
\hline c & $w$ & [w] & $c[w]$ \\
\hline 35 & .31 & .31 & 10.85 \\
\hline 34 & $.31 \quad .64$ & .95 & 32.30 \\
\hline 71 & $.64 \quad .66$ & 1.30 & 92.30 \\
\hline 19 & $\begin{array}{ll}.66 & .69\end{array}$ & 1.35 & 25.65 \\
\hline 21 & $\begin{array}{ll}.69 & .71\end{array}$ & 1.40 & 29.40 \\
\hline 24 & $\begin{array}{ll}.71 & .74\end{array}$ & 1.45 & 34.80 \\
\hline 30 & $.74 \quad .75$ & 1.49 & 44.70 \\
\hline
\end{tabular}

summation with improved weights

$$
\begin{array}{rrrrrr} 
& . w & & {[w]} & f[w] \\
.66 & .69 & 2 .- & 3.35 & 6.70 \\
.71 & .74 & 2 .- & 3.45 & 3.45 \\
& & & 4 .- & 44 .- \\
& & & 4 .- & 36 .- \\
& & & 4 .- & 76 .- \\
& & & 4 .- & 76 .- \\
& & & 4 .- & 72 .- \\
& & & & & \\
& & & & & \\
& & & &
\end{array}
$$

Neth. J. agric. Sci., Vol. 11 (1963) No. 4 (August) 


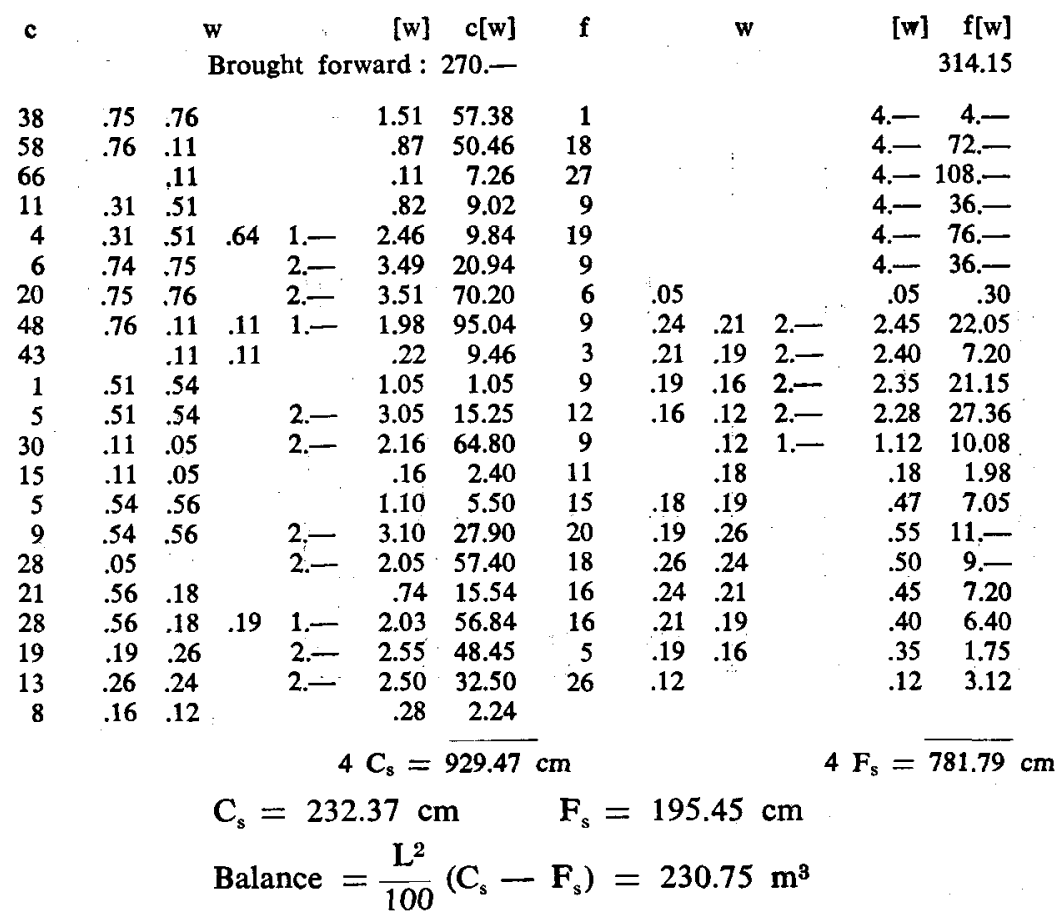

Four-point calculation

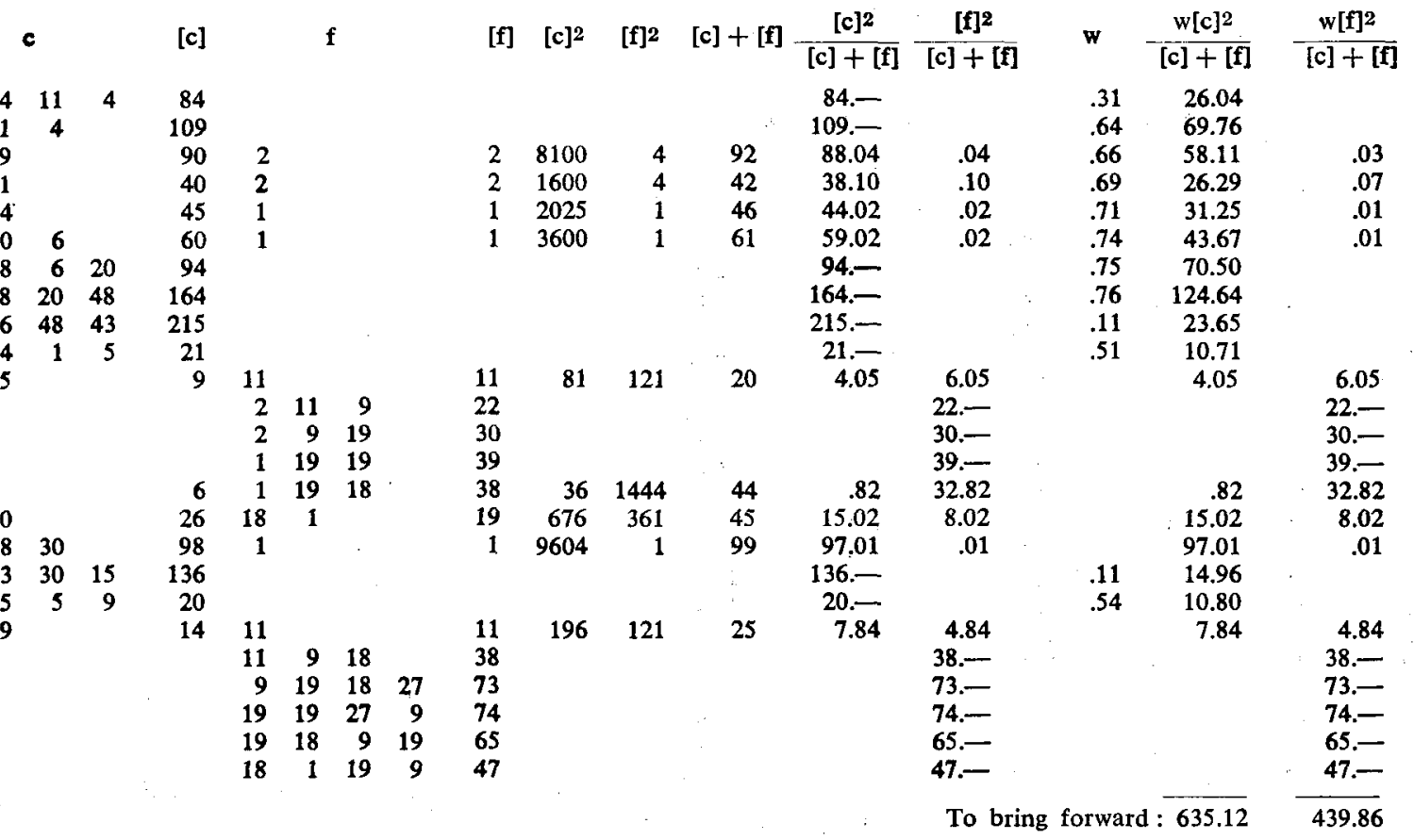






Four-point correction of summation with improved weights

\begin{tabular}{|c|c|c|c|c|c|c|}
\hline [c] & [f] & w & {$[c] \times[\mathbf{f}]$} & $\frac{w}{[c]+[f]}$ & $\frac{w[c][f]}{[c]+[f]}$ & \\
\hline 90 & 2 & .66 & 180 & .0072 & 1.30 & \\
\hline 40 & 2 & .69 & 80 & .0164 & 1.31 & \\
\hline 45 & 1 & .71 & 45 & .0154 & .69 & \\
\hline 60 & 1 & .74 & 60 & .0121 & .73 & \\
\hline 9 & 11 & & 99 & .0500 & 4.95 & \\
\hline 6 & 38 & & 228 & .0227 & 5.18 & \\
\hline 26 & 19 & & 494 & .0222 & 10.97 & \\
\hline 98 & 1 & & 98 & .0101 & .99 & \\
\hline 14 & 11 & & 154 & .0400 & 6.16 & \\
\hline 58 & 10 & & 580 & .0147 & 8.53 & \\
\hline 73 & 6 & .05 & 438 & .0006 & .26 & \\
\hline 32 & 18 & & 576 & .0200 & 11.52 & $D_{\mathrm{f}}=23.76 \mathrm{~cm}$ \\
\hline 13 & 54 & & 702 & .0149 & 10.46 & $\mathrm{C}_{f}=\mathrm{C}_{s}-\mathrm{D}_{f}=208.61 \mathrm{~cm}$ \\
\hline 28 & 30 & & 840 & .0172 & 14.45 & $C_{f}=C_{s}-D_{f}=208.61 \mathrm{~cm}$ \\
\hline 49 & 26 & .18 & 1274 & .0024 & 3.06 & $F_{f}=F_{s}-D_{f}=171.69 \mathrm{~cm}$ \\
\hline 47 & 35 & .29 & 1645 & .0035 & 5.76 & $f_{f}-I_{2}$ \\
\hline 32 & 38 & .26 & 1216 & .0037 & 4.50 & $V_{c_{f}}=\frac{L^{2}}{100} C_{f}$ \\
\hline 13 & 43 & .24 & 559 & .0043 & 2.40 & $c_{f}-100$ \\
\hline $\begin{array}{l}8 \\
8\end{array}$ & $\begin{array}{l}26 \\
47\end{array}$ & $\begin{array}{l}.16 \\
.12\end{array}$ & $\begin{array}{l}208 \\
376\end{array}$ & $\begin{array}{l}.0047 \\
.0022\end{array}$ & $\begin{array}{l}.98 \\
.83\end{array}$ & $L^{2}$ \\
\hline & & .12 & 310 & $4 D_{f}$ & $95.03 \mathrm{~cm}$ & $I_{f_{f}}=\frac{L}{100} F_{f}=1073.06 n$ \\
\hline
\end{tabular}


THE MATHEMATICAL TREATMENT OF GRID-SURVEY DATA FOR LAND LEVELLING

Stereometric correction of summation with improved weights

Diagonal division: upper right - lower left Diagonal division: upper left - lower right

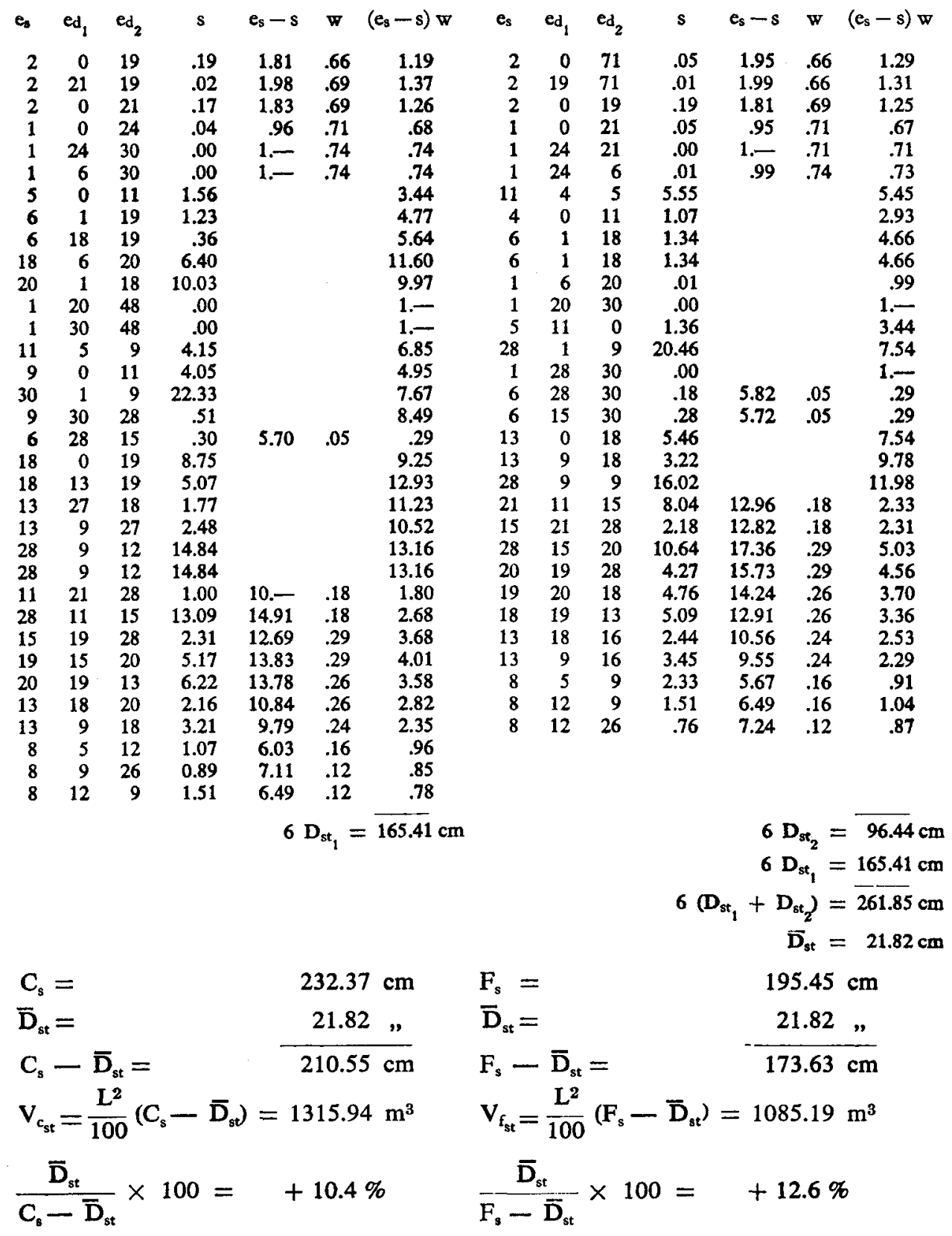


J. L. UNGER

Plot 1

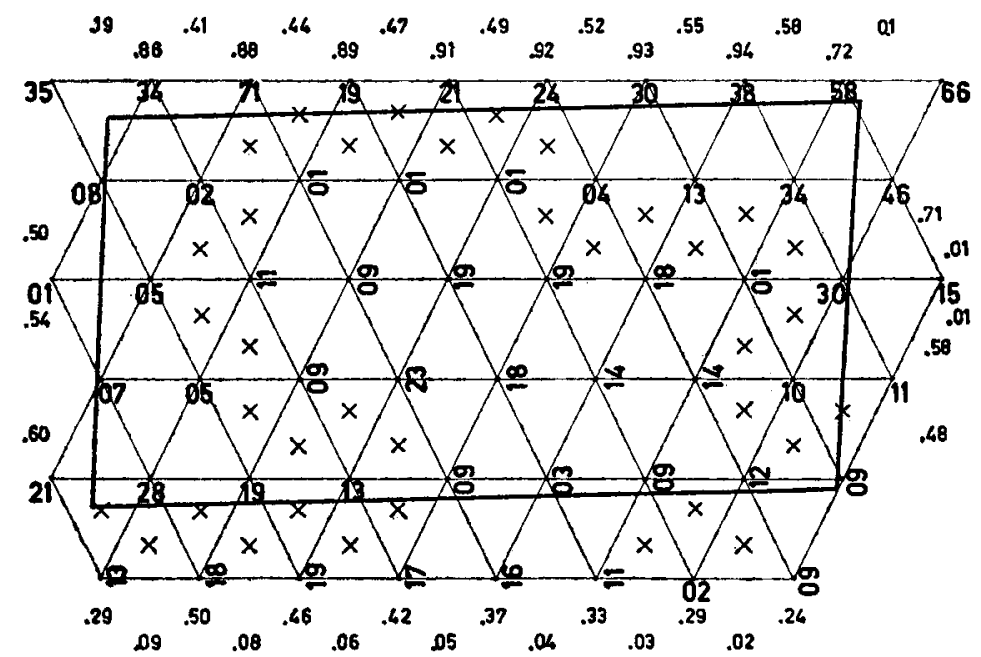

FIGURE 10

Pl ot 1. Isosceles $\triangle$-net (FIG. 10)

Summation with improved weights

\begin{tabular}{|c|c|c|c|c|c|c|c|c|c|c|c|c|c|c|}
\hline c & & & w & & & [w] & c [w] & f & & & $\mathbf{w}$ & & [w] & $f[w]$ \\
\hline 35 & .19 & & & & & .19 & 6.65 & 1 & .88 & .44 & .89 & 3.- & 5.21 & 5.21 \\
\hline 34 & .19 & .86 & .41 & & & 1.46 & 49.64 & 1 & .89 & .47 & .91 & 3.- & 5.27 & 5.27 \\
\hline 71 & .41 & .88 & .44 & & & 1.73 & 122.83 & 1 & .91 & .49 & .92 & 3.- & 5.32 & 5.32 \\
\hline 19 & .44 & .89 & .47 & & & 1.80 & 34.20 & 11 & & & & & 6.- & 66.- \\
\hline 21 & .47 & .91 & .49 & & & 1.87 & 39.27 & 9 & & & & & 6.- & 54.- \\
\hline 24 & .49 & .92 & .52 & & & 1.93 & 47.32 & 19 & & & & & 6.- & 114. - \\
\hline 30 & .52 & .93 & .55 & & & 2.00 & 60.00 & 19 & & & & & 6.- & 114 \\
\hline 38 & .55 & .94 & .58 & & & 2.07 & 78.66 & 18 & & & & & 6.- & 108.- \\
\hline 58 & .58 & .72 & .01 & & & 1.31 & 75.98 & 1 & & & & & 6.- & 6.- \\
\hline 66 & & & .01 & & & .01 & .66 & 9 & & & & & 6.- & 54.- \\
\hline 8 & .50 & .19 & .86 & & & 2.55 & 20.40 & 23 & & & & & 6.- & 138.- \\
\hline 2 & .86 & .41 & .88 & & 3.- & 5.15 & 10.30 & 18 & & & & & 6.- & 108.- \\
\hline 4 & .92 & .52 & .93 & & 3.- & 5.37 & 21.48 & 14 & & & & & 6.- & 84.- \\
\hline 13 & .93 & .55 & .94 & & 3.- & 5.42 & 70.46 & 14 & & & & & 6.- & 84.- \\
\hline 34 & .94 & .58 & .72 & .71 & 2.- & 4.95 & 168.30 & 9 & .37 & .05 & .42 & 3.- & 3.84 & 34.56 \\
\hline 46 & .72 & .01 & .01 & .71 & & 1.45 & 66.70 & 3 & .33 & .04 & .37 & 3.- & 3.74 & 11.22 \\
\hline 1 & .50 & .54 & & & & 1.04 & 1.04 & 9 & .29 & .03 & .33 & 3.- & 3.65 & 32.85 \\
\hline 5 & .50 & .54 & & & 4.- & 5.04 & 25.20 & 12 & .24 & .02 & .29 & 3.- & 3.55 & 42.60 \\
\hline 30 & .71 & .01 & .01 & .58 & 2.- & 3.31 & 99.30 & 9 & .24 & .48 & & 1.- & 1.72 & 15.48 \\
\hline 15 & .01 & .01 & & & & .02 & .30 & 13 & .09 & .29 & & & .38 & 4.94 \\
\hline 7 & .54 & .60 & & & 2.- & 3.14 & 21.98 & 18 & .09 & .50 & .08 & & .67 & 12.06 \\
\hline 5 & & & & & 6.- & 6.- & 30.- & 19 & .08 & .46 & .06 & & .60 & 11.40 \\
\hline 10 & .58 & .48 & & & 4.- & 5.06 & 50.60 & 17 & .06 & .42 & .05 & & .53 & 9.01 \\
\hline 11 & .48 & .58 & .01 & & & 1.07 & 11.77 & 16 & .05 & .37 & .04 & & .46 & 7.36 \\
\hline 21 & .60 & .29 & & & & .89 & 18.69 & 11 & .04 & .33 & .03 & & .40 & 4.40 \\
\hline 28 & .50 & .09 & .29 & .60 & 2.- & 3.48 & 97.44 & 9 & .02 & .24 & & & .26 & 2.34 \\
\hline 19 & .46 & .08 & .50 & & 3.- & 4.04 & 76.76 & & & & & & & \\
\hline 13 & .42 & .06 & .46 & & 3.- & 3.94 & 51.22 & & & & & & & \\
\hline 2 & .03 & .29 & .02 & & & .34 & .68 & & & & & & & \\
\hline & & & & & & $C_{s}=$ & 356.83 & & & & & & $F_{s}=$ & 134.11 \\
\hline
\end{tabular}


THE MATHEMATICAL TREATMENT OF GRID-SURVEY DATA FOR LAND LEVELLING

$$
\begin{array}{rlrl}
C_{s}= & 226.14 \mathrm{~cm} & F_{s}= & 189.02 \mathrm{~cm} \\
\frac{L^{2}}{100}= & 6.25 & \text { Balance }=\frac{L^{2}}{100}\left(C_{s}-F_{s}\right)=232.00 \mathrm{~m}^{3}
\end{array}
$$

Stereometric correction of summation with improved weights

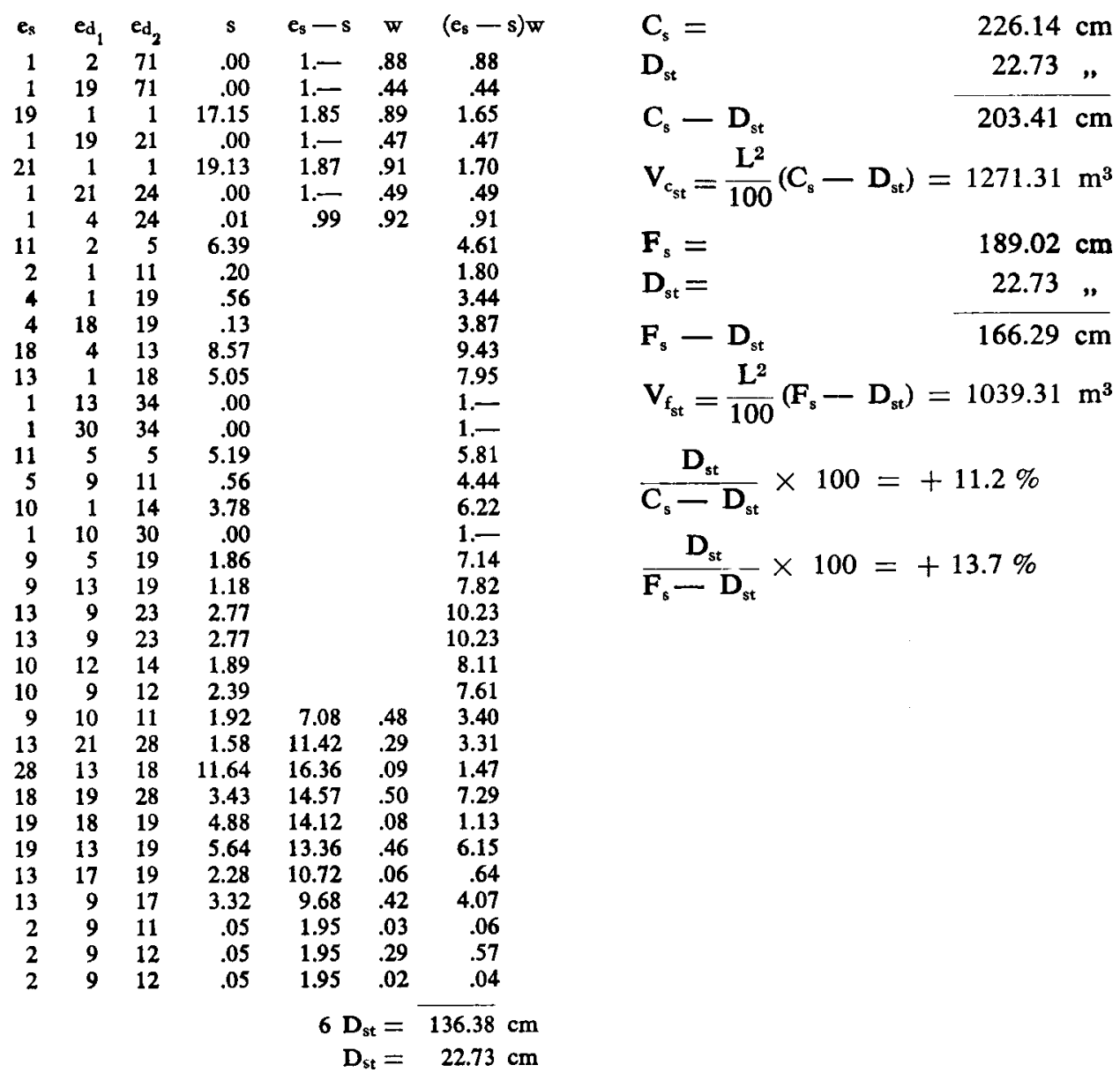

Calculation results plot 2 (FIG. 11)

Summation

$$
\begin{aligned}
& V_{c}=1381.31 \mathrm{~m}^{3} \\
& V_{f}=1692.75 \mathrm{~m}^{3} \quad \text { Balance }=-311.44 \mathrm{~m}^{3}
\end{aligned}
$$

Summ. with impr. weights $\quad V_{c_{s}}=1461.75 \mathrm{~m}^{3}$$$
\mathrm{V}_{\mathrm{f}_{\mathrm{s}}}=1707.63 \mathrm{~m}^{3} \quad \text { Balance }=-245.88 \mathrm{~m}^{3}
$$

Four point

$$
\begin{aligned}
& V_{c_{\mathrm{f}}}=1220.31 \mathrm{~m}^{3} \\
& V_{\mathrm{f}_{\mathrm{f}}}=1466.19 \mathrm{~m}^{3} \quad \text { Balance }=-245.88 \mathrm{~m}^{3}
\end{aligned}
$$


Stereometric

$$
\begin{aligned}
& V_{c_{s t}}=1223.12 \mathrm{~m}^{3} \\
& V_{\mathrm{f}_{\mathrm{st}}}=1469.00 \mathrm{~m}^{3} \quad \text { Balance }=-245.88 \mathrm{~m}^{3}
\end{aligned}
$$

Errors summ. with impr. weights $\frac{V_{c_{s}}-V_{c_{\text {st }}}}{V_{c_{s t}}} \times 100=+19.5 \%$

$$
\frac{V_{f_{s}}-V_{f_{s t}}}{V_{f_{s t}}} \times 100=+16.2 \%
$$

Errors four-point method

$$
\begin{aligned}
& \frac{\mathrm{V}_{\mathrm{cf}_{\mathrm{f}}}-\mathrm{V}_{\mathrm{c}_{\mathrm{st}}}}{\mathrm{V}_{\mathrm{cst}_{\mathrm{st}}}} \times 100=-.2 \% \\
& \frac{\mathrm{V}_{\mathrm{f}_{\mathrm{f}}}-\mathrm{V}_{\mathrm{f}_{\mathrm{st}}}}{\mathrm{V}_{\mathrm{fst}_{\mathrm{st}}}} \times 100=-.2 \%
\end{aligned}
$$

\section{Plot 2}

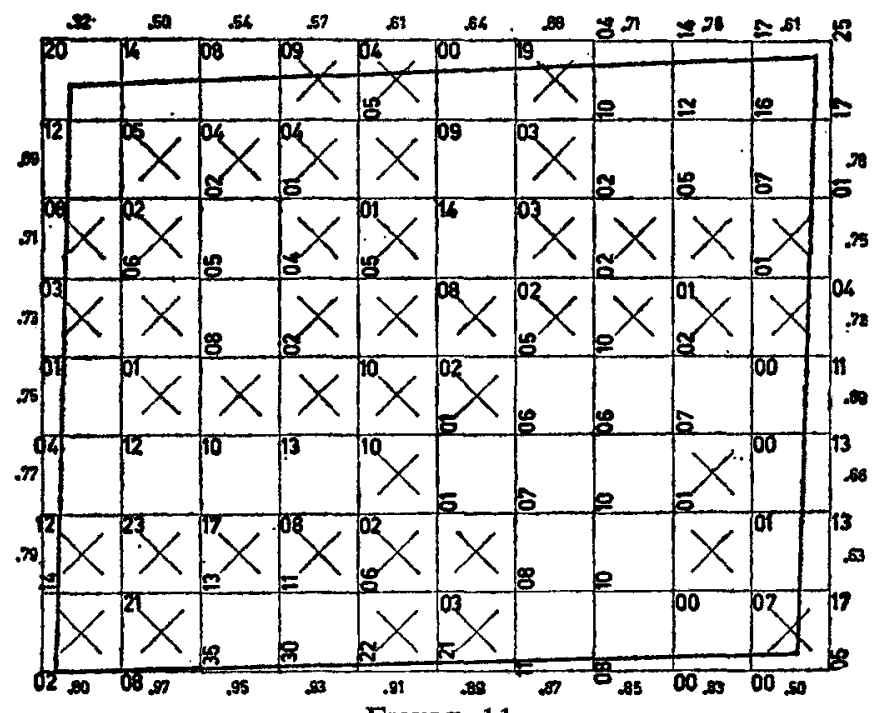

FIGURE 11

Calculation results plot 3 (FIG. 12)

Summation

Summ. with impr. weights

Four point

Stereometric
$\mathrm{V}_{\mathrm{c}}=818.50 \mathrm{~m}^{3}$

$\mathrm{V}_{\mathrm{f}}=853.81 \mathrm{~m}^{3} \quad$ Balance $=-35.31 \mathrm{~m}^{3}$

$\mathrm{V}_{\mathrm{c}_{\mathrm{s}}}=988.13 \cdot \mathrm{m}^{3}$

$\mathrm{V}_{\mathrm{f}_{\mathrm{s}}}=876.63 \mathrm{~m}^{3} \quad$ Balance $=+111.50 \mathrm{~m}^{3}$

$\mathrm{V}_{\mathrm{c}_{\mathrm{f}}}=833.38 \mathrm{~m}^{3}$

$\mathrm{V}_{\mathrm{f}_{\mathrm{f}}}=721.88 \mathrm{~m}^{3} \quad$ Balance $=+111.50 \mathrm{~m}^{3}$

$\mathrm{V}_{\mathrm{c}_{\mathrm{st}}}=842.63 \mathrm{~m}^{3}$

$\mathrm{V}_{\mathrm{fst}_{\mathrm{st}}}=731.13 \mathrm{~m}^{3} \quad$ Balance $=+111.50 \mathrm{~m}^{3}$

Neth. J. agric. Sci., Vol. 11 (1963) No. 4 (August) 
THE MATHEMATICAL TREATMENT OF GRID-SURVEY DATA FOR LAND LEVELLING

Errors summ. with impr. weights $\frac{V_{c_{s}}-V_{c_{s t}}}{V_{c_{s t}}} \times 100=+17.3 \%$

$$
\frac{V_{f_{s}}-V_{f_{s t}}}{V_{f_{s t}}} \times 100=+19.9 \%
$$

Errors four-point method

$$
\begin{aligned}
& \frac{V_{c_{f}}-V_{c_{s t}}}{V_{c_{s t}}} \times 100=-1.1 \% \\
& \frac{V_{f_{f}}-V_{f_{s t}}}{V_{f_{s t}}} \times 100=-1.3 \%
\end{aligned}
$$

\section{Plot 3}

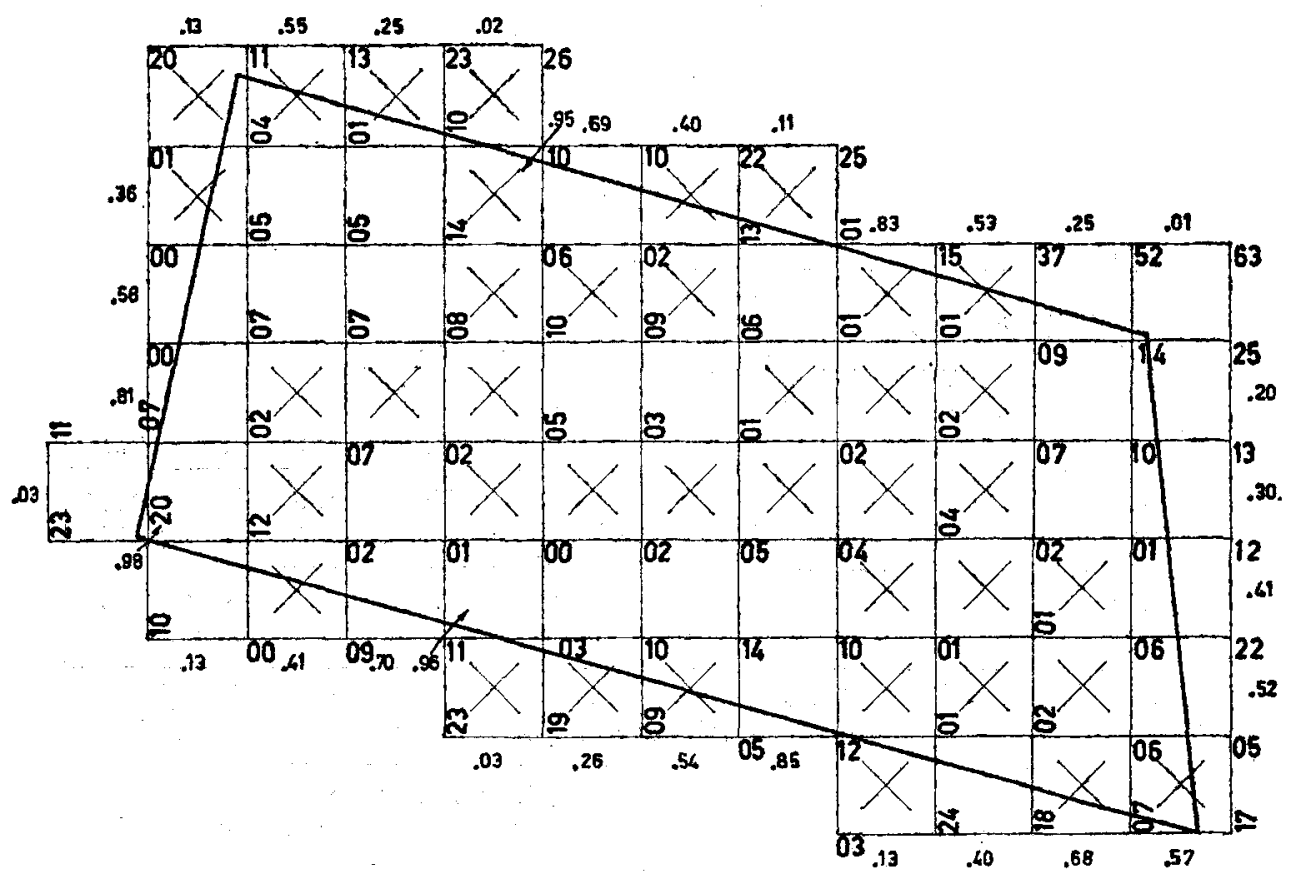

FIGURE 12

Calculation results plot 4 (FIG. 13)

Summation

Summ. with impr. weights

$$
\begin{aligned}
& V_{f}=1139.63 \mathrm{~m}^{3} \\
& V_{f}=1081.63 \mathrm{~m}^{3} \quad \text { Balance }=+58.00 \mathrm{~m}^{3} \\
& V_{c_{s}}=1220.19 \mathrm{~m}^{3} \\
& \mathbf{V}_{f_{s}}=1186.56 \mathrm{~m}^{3} \quad \text { Balance }=+33.63 \mathrm{~m}^{3}
\end{aligned}
$$

Neth. J. agric. Sci., Vol. II (1963) No. 4 (August) 
Four point

Stereometric

Errors four-point method
$V_{c_{\mathrm{f}}}=998.69 \mathrm{~m}^{3}$

$\mathrm{V}_{\mathrm{f}_{\mathrm{f}}}=965.06 \mathrm{~m}^{3} \quad$ Balance $=+33.63 \mathrm{~m}^{3}$

$V_{c_{s t}}=1021.00 \mathrm{~m}^{3}$

$\mathrm{V}_{\mathrm{f}_{\mathrm{st}}}=987.38 \mathrm{~m}^{3} \quad$ Balance $=+33.62 \mathrm{~m}^{3}$

Errors summ. with impr. weights $\frac{V_{c_{s}}-V_{c_{s t}}}{V_{c_{s t}}} \times 100=+19.5 \%$

$$
\frac{V_{f_{s}}-V_{f_{s t}}}{V_{f_{s t}}} \times 100=+20.2 \%
$$

$\frac{V_{c_{f}}-V_{c_{s t}}}{V_{c_{s t}}} \times 100=-2.2 \%$

$\frac{V_{f_{f}}-V_{f_{s t}}}{V_{f_{s t}}} \times 100=-2.3 \%$

\section{PloT 4}

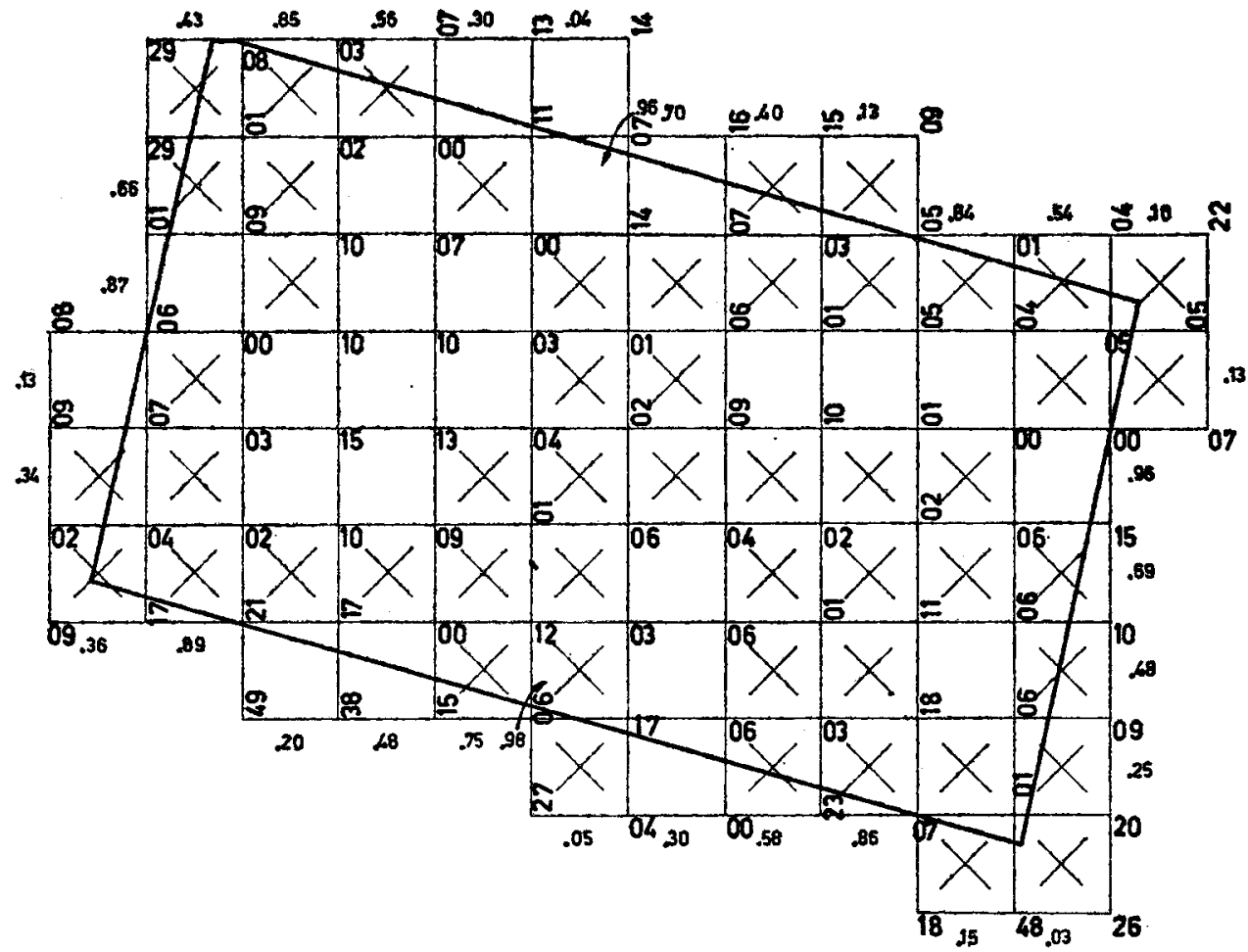

FIGURE 13 
The results of these examples confirm the trends mentioned before. It is remarkable that in these cases the errors of the four-point method are very small and all negative. The difference between the results of summation in the usual manner and the results of the stereometric calculation is smaller than the difference between the results of summation with improved weights and the results of the stereometric calculation. Since, however, the earth-work balances are not comparable, comparison of the differences does not lead to satisfying conclusions.

\section{Tentative comparison between calculated and true volumes}

So far it has been demonstrated that the summation method gives bigger volumes compared with those calculated with the aid of the four-point and stereometric methods. The correctness of the assumption that the latter two methods give a better approximation of the true volumes to be moved than the former remains to be investigated. In FIG. 14, the results of the various calculation methods are compared for grids where cut changes to fill showing five types of slope: linear, convex, concave, sinusoidal convex-concave and sinusoidal concave-convex. For each type the same cut and fill values are used, pertaining to the two end planes at the left and the right and to the middle section (parallel to the end planes). So, for all types of slope the results calculated on account of the cut and fill values in the four corners of the grid square are the same for each method. Since comparison of the cut and fill values shows that the position of the present surface is the same for each set of sections, whereas the future surface is a plane showing a linear slope perpendicular to the plane of drawing, the true volumes to be moved are either bounded by planes only or by planes and surfaces bent in one direction only, namely parallel to the plane of drawing, in case of the second up to and including the fifth type of slope. Under these circumstances, it is possible to calculate the true volumes by means of the prismoidal formula.

Calculation of the volumes of cut and fill when

$\begin{array}{lll}c_{1}=5 \mathrm{~cm} & f_{1}=15 \mathrm{~cm} & \mathrm{~L}=50 \mathrm{~m} \\ c_{2}=15 \mathrm{~cm} & \mathrm{f}_{2}=5 \mathrm{~cm} & \end{array}$

gives the following results :

\begin{tabular}{lrr} 
& $V_{c}$ & \multicolumn{1}{c}{$V_{f}$} \\
summation & $125 .-\mathrm{m}^{3}$ & $125 .-\mathrm{m}^{3}$ \\
four point & $62.50 \mathrm{~m}^{3}$ & $62.50 \mathrm{~m}^{3}$ \\
stereometric & $67.71 \mathrm{~m}^{3}$ & $67.71 \mathrm{~m}^{3}$
\end{tabular}

Comparison of these values with those calculated with the aid of the prismoidal formula shows the following differences (all volumes in $\mathrm{m}^{3}$ ):

1. Linear slope summation four point stereometric

2. Circular convex slope summation four point stereometric

$$
\begin{aligned}
& \text { true } \mathrm{V}_{\mathrm{c}} \text { true } \mathrm{V}_{\mathrm{f}} \quad \Delta \mathrm{V}_{\mathrm{c}} \quad \Delta \mathrm{V}_{\mathrm{f}} \\
& 67.71 \quad 67.71 \\
& +57.29=+85 \%+57.29=+85 \% \\
& -5.21=-8 \%-5.21=-8 \%
\end{aligned}
$$

$108.07 \quad 21.63$

$$
\begin{aligned}
-55.07 & =-31 \%+103.37=+476 \% \\
-117.57 & =-65 \%+40.87=+188 \% \\
-112.36 & =-62 \%+46.08=+212 \%
\end{aligned}
$$





3

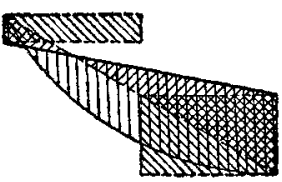

4
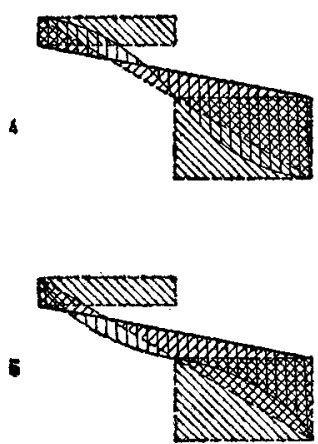
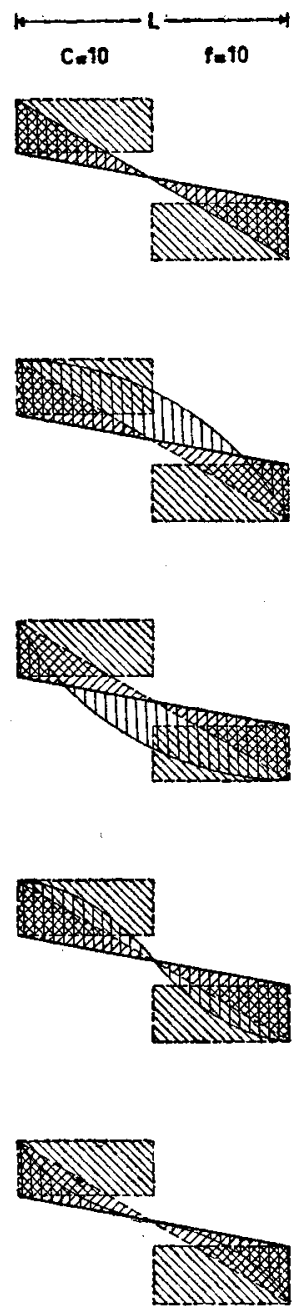
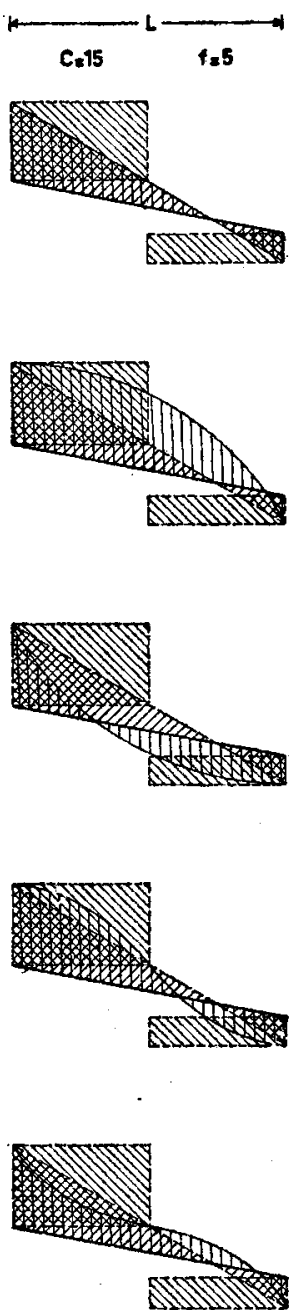

Differences in volumes of earth movement in grid squares, where cut changes to fill, for five cases with constant grid-polnt figures but varying slope, when calculated according to the Summation method Stereomatric method

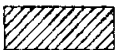

Actual volumes

Present surface

Future surfece

FIGURE 14 
3. Circular concave slope summation four point stereometric

4. Sinusoidal convex-concave slope summation four point stereometric

5. SinusoidaJ concave-convex slope summation four point stereometric

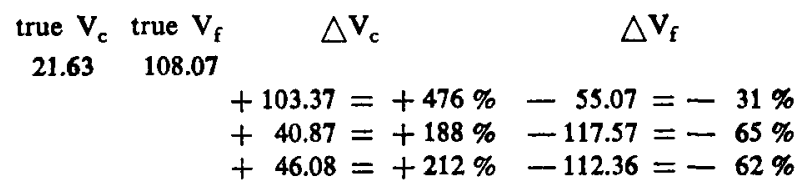

$92.83 \quad 92.83$

$+32.17=+35 \%+32.17=+35 \%$

$-30.33=-33 \%-30.33=-33 \%$

$-25.12=-27 \%-25.12=-27 \%$

47.17
47.17

$$
\begin{aligned}
& +77.83=+165 \%+77.83=+165 \% \\
& +15.33=+32 \%+15.33=+32 \% \\
& +20.54=+43 \%+20.54=+43 \%
\end{aligned}
$$

$$
\begin{aligned}
& \text { Mean true } V_{c}=81.88, \text { true } V_{f}=81.88 \text {, true balance }=0 \\
& \text { summation } \\
& \text { four point } \\
& \text { stereometric } \\
& \begin{aligned}
\Delta \mathrm{V}_{\mathrm{c}}=+43.12 & =+53 \% \\
-19.38 & =-24 \% \\
-14.17 & =-17 \%
\end{aligned} \\
& \begin{aligned}
\triangle \mathrm{V}_{\mathrm{f}}=+43.12 & =+53 \% \\
-19.38 & =-24 \% \\
-14.17 & =-17 \%
\end{aligned} \\
& \text { balance } 0 \\
& \triangle V_{c}=+45.89=+64 \% \quad \triangle V_{f}=+37.55=+49 \% \\
& -16.61=-23 \% \\
& -24.95=-33 \% \\
& -19.74=-26 \% \\
& \begin{array}{r}
\text { balance }+3.79 \\
+3.79 \\
+3.79
\end{array} \\
& -11.40=-16 \%
\end{aligned}
$$

It appears from the above figures that the volumes calculated following the summation, four-point or stereometric method may differ appreciably from the true volumes. There is a noticeable difference between the results of the summation method and those of the four-point and stereometric methods, the former remaining below the true values only twice, the latter doing so repeatedly. As a result, the arithmetical mean of the summation figures is too great, both for cut and for fill, whereas the four-point and stereometric figures are too small. The ratio summation difference: stereometric difference is about $3: 1$; bigger than the ratio of the summation and four-point differences, and, therefore, in favour of the stereometric calculation.

The situations represented in FIG. 14 are not equally likely to occur in reality. A better approximation of the average true conditions is obtained by calculating weighed means, although the apportioning of weights is never free from arbitrariness. Taking into account a probably more or less frequent occurrence of the various situations under average conditions, the following weights have been attributed:

$\begin{array}{ccccc}\text { slope type } & 1 & \text { weight } & 7 \\ \text {, " } & 2 & \text { " } & 2 \\ \text {, " } & 3 & , & 3 \\ \text { ", } & 4 & 5 & 6 \\ & \text {, } & 5 & , & 1\end{array}$

The results show the same trend as the arithmetical means, with, however, one important difference; the balance calculated according to the three above-mentioned methods is almost the opposite of the true balance. As a result, the balance will show a deficit of $3.79+4.55=8.34 \mathrm{~m}^{3}$ or about $11 \%$ of the true volumes to be moved. Similar phenomena are repeatedly observed in practice. 
It is understandable that many other types of slopes will occur in practice as well and that the frequencies of occurrence may differ appreciably from those taken into account when attributing the above-mentioned weights. The example given in FIO. 14 serves two purposes only :

a. to demonstrate the approximative character of any calculation;

b. to demonstrate the trend of the stereometric calculation to give the closest approximation on an average.
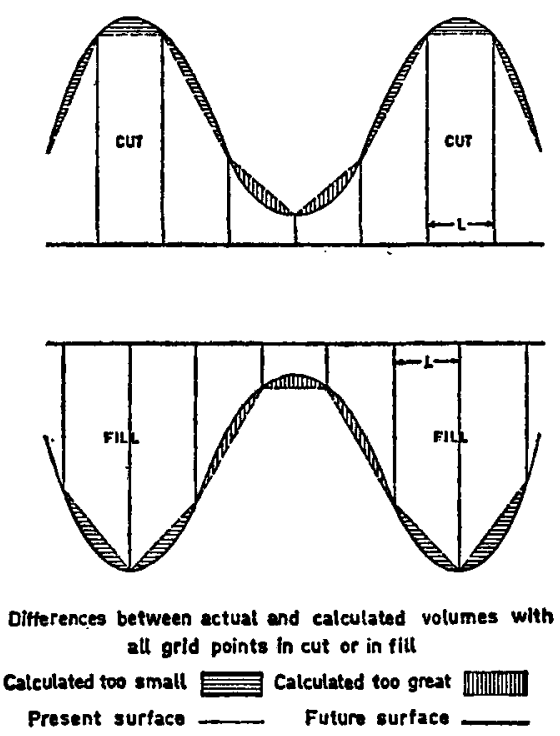

FIGURE 15

In FIG. 15, two cross sections of grid squares with all points in cut and in fill have been drawn. Since, in such cases, all three methods of calculation give identical results, the cross sections of the calculated volumes are represented by drawing straight lines between the grid points.

It is apparent that, when all grid points are in cut, the calculated volumes exceed or fall short of the true volumes according as to whether the relief shows a concave or a convex surface respectively, or the reverse, when all grid points are in fill. These circumstances too will influence the exactness of an earth-work balance. 